

\section{Sumário}

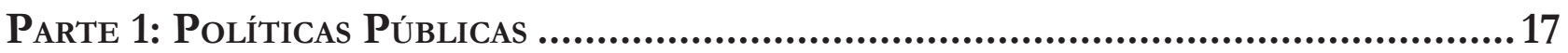

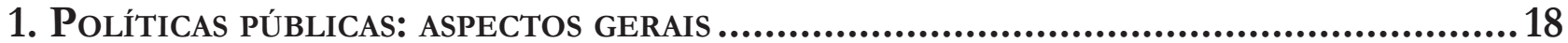

UM MODELO POLÍTICO DE IMPLEMENTAÇÃO PARA AS POLÍTICAS PÚBLICAS: OS PAPÉIS DO DIREITO E DOS JURISTAS.

William H. Clune III

Evaluación de las obras públicas en gobiernos locales en MÉxico: Desafíos de LaS POLÍTICAS PÚBLICAS DE PARTICIPACIÓN CIUDADANA

Louis Valentin Mballa e Arturo Bermúdez Lara

Paternalismo libertário e políticas públicas: intervenção e transparênCia

Marcia Carla Pereira Ribeiro e Victor Hugo Domingues

2. Políticas públicas E COVID-19

LiMITES E POSSIBILIDADES PARA O USO SECUNDÁRIO DE DADOS PESSOAIS NO PODER PÚBLICO: LIÇÕES DA PANDEMIA.

Miriam Wimmer

EFICIÊNCIA DAS POLÍTICAS DE INOVAÇÃO NOS SETORES INDUSTRIAIS BRASILEIROS: SUGESTÕES PARA A CRISE DA COVID-19

Michelle Márcia Viana Martins e Chrystian Soares Mendes

CoMPLIANCE EM TEMPOS DE CALAMIDADE PÚbLICA: ANÁLISE SOBRE A FLEXIBILIZAÇÃo DA TRANSPARÊNCIA DE DADOS E INFORMAÇÕES DURANTE O ENFRENTAMENTO DA COVID-19 NO BrasiL

Luciana Cristina da Conceição Lima, Alcindo Fernandes Gonçalves, Fernando Cardoso Fernandes Rei e Cláudio Benevenuto de Campos Lima

3. Políticas públicas e accountability

ACCOUNTABility E DESENHO INSTITUCIONAL: UM “PONTO CEGO" NO DIREITO PÚBLICO BRASILEIRO

Danielle Hanna Rached

ESTRATÉGIAS REGULATÓRIAS DE COMBATE À CORRUPÇÃo 
O controle e a avaliação pelo Tribunal de Contas da União das políticas públicas IMPLEMENTADAS POR DESONERAÇÕES TRIBUTÁRIAS NO BRASIL

Vinicius Garcia e Carlos Araújo Leonetti

4. Políticas públicas em Matéria de SAÚde

A livre opÇão pela Cesariana: um "NUdge Às aVessas". .268

Bruna Menezes Gomes da Silva e Júlio Cesar de Aguiar

AUTISMO: ASPECTOS JURÍDICOS DA ACESSIBILIDADE E RESPEITO

Fabiana Barrocas Alves Farah e Danilo Fontenele Sampaio Cunha

SAÚdE E DOENÇAS RARAS: ANÁLISE DA JUDICIALIZAÇÃo DO ACESSO AO TRATAMENTO E SUAS LIMITAÇÕES.

Danilo Henrique Nunes e Lucas de Souza Lehfeld

5. OUTRAS POLÍTICAS PÚBLICAS EM ESPÉCIE

REGUlAÇÃO DAS ÁGUAS: UMA ANÁLISE EMPÍRICA DA PRODUÇÃo NORMATIVA DOS ÓRGÃOS REGULADORES FEDERAIS

Bianca Borges Medeiros Pavão, Natasha Schmitt Caccia Salinas e Thauany do Nascimento Vigar

“LET THE ALGORITHM DECIDE": IS HUMAN DIGNITY AT STAKE?.

Marcela Mattiuzzo

DAS ACEPÇÕES DOS DIREITOS DOS REFUGIADOS ÀS VOZES SILENCIADAS NAS POLÍTICAS PÚBLICAs371 Thaís Araújo Dias e Monica Mota Tassigny

Planejamento familiar: “inimigo" a Ser combatido, “aliado” libertador ou falso "AMIGO"?

Vinicius Ferreira Baptista

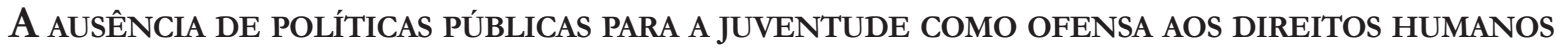
William Timóteo e llzver de Matos Oliveira

AnÁlise CÊniCa dos feminicídios em Curitiba: propostas preventivas e repressivas ....433 Ticiane Louise Santana Pereira, Octahydes Ballan Junior e Antonio Henrique Graciano Suxberger

ORIGIN AND CONSEQUENCES OF THE WAR ON DRUGS. FROM THE UNITED STATES TO ANDEAN COUNTRIES

Silvio Cuneo e Nicolás Oxman 
Trabalho Decente: comportamento Ético, política pública ou Bem JuRIDiCamente TUTELADO?.

Silvio Beltramelli Neto e Mônica Nogueira Rodrigues

El FINAL DE UNA POLÍtica PÚBLICA: ANÁLISIS DEL CICLO POLÍTICO DEL PROYECTO DESTINOS INDUCTORES PARA EL DESARROLLO TURISTICO REGIONAL (DIDTR) - BRASIL. .496

María Belén Zambrano Pontón, Magnus Luiz Emmendoerfer e Suely de Fátima Ramos Silveira

Alternativa tecnológica para COMPensaÇão de CRÉditos de ICMS: ESTUdo de Caso da VIABILIDADE DO USO DE DLT EM NOTA FISCAL ELETRÔNICA .520

Danielle Mendes Thame Denny, Roberto Ferreira Paulo e Fernando Crespo Queiroz Neves

Parte 2: Temas Gerais

A construção do Direito Humano ao Alimento no plano internacional. 551 Tatiana de A. F. R. Cardoso Squeff

Grupos vUlNERABles de ESPECIAL PROTECCIÓN POR PARTE DEL INSTITUTO NACIONAL DE Derechos Humanos (INDH) ¿EN QUIÉN PODRÍA Y DEBERÍA ENFOCARSE EN BASE A LA DOCTRINA Y A LA EXPERIENCIA COMPARADA IBEROAMERICANA?

Juan Pablo Díaz Fuenzalida

El SUFRAGIO ELECTRÓNICO COMO ALTERNATIVA AL SUFRAGIO TRADICIONAL: LUCES Y SOMBRAS DE UN DEBATE RECURRENTE 595

David Almagro Castro, Felipe Ignacio Paredes Paredes e Edgardo Lito Andres Cancino

Cognoscibilidade E CONTROLE SOCIAL dA TRANSPARÊNCIA PÚbliCA SOB A ÉGIDE DA DEMODIVERSIDADE: ESTUDO EMPÍRICO DE PORTAIS ELETRÔNICOS MINISTERIAIS LATINOAMERICANOS

Ana Carolina Campara Verdum, Leonardo Fontana Trevisan e Rosane Leal da Silva

DESAFIOS E BENEFÍCIOS DA INTELIGÊNCIA ARTIFICIAL PARA O DIREITO DO CONSUMIDOR 655 Sthéfano Bruno Santos Divino

QUEM TEM MEDO DA RESPONSABILIZAÇÃo SUBJETIVA? As TEORIAS DA CONDUTA E DA IMPUTAÇÃO, PARA UM DIREITO ADMINISTRATIVO SANCIONADOR CONSTITUCIONALIZADO...........................690 Sandro Lúcio Dezan e Paulo Afonso Cavichioli Carmona

A INSUfiCiÊNCIA dE TRIBUTAÇÃo COMO FUNDAMENTO PARA O AFASTAMENTO DA RESERVA DO POSSÍVEL NA GARANTIA DO MÍNIMO EXISTENCIAL E DA DIGNIDADE HUMANA. 711 Dione J. Wasilewski e Emerson Gabardo 


\title{
Grupos vulnerables de especial protección por parte del Instituto Nacional de Derechos Humanos (INDH) ¿en quién podría y debería enfocarse en base a la doctrina y a la experiencia comparada iberoamericana?
}

\author{
Vulnerable groups of special protection \\ by the National Institute of Human Rights \\ (NIHR) who could and should focus on based \\ on the doctrine and comparative ibero- \\ american experience?
}

Juan Pablo Díaz Fuenzalida**

\section{Resumen}

El presente artículo estudia al Instituto Nacional de Derechos Humanos (INDH) de Chile en su actividad de promoción y protección de los derechos humanos, concretamente en la coherencia de enfocarse en determinados grupos vulnerables, a propósito de sus 10 años de existencia. La hipótesis que guía la investigación es que las figuras jurídicas de promoción y protección de los derechos humanos (originadas por los Principios de París o en aplicación de estos) deben considerar estrategias para dar mayor efectividad en su quehacer, pudiendo enfocarse en los más desamparados. Para el ejercicio de comprobación y generación de reflexiones, se utiliza el método dogmático en relación con la doctrina especializada sobre grupos vulnerables. Además, con el método empírico se revisa el enfoque de especial protección por parte de las instituciones nacionales de derechos humanos en Iberoamérica pudiendo generar puntos en común y diferencias relevantes que sirven de buenas prácticas. Destaca como conclusión que los grupos de especial protección en que se ha enfocado el INDH son coherentes con la doctrina y experiencia de las otras defensorías, pero que, sin embargo, habría que considerar a otras colectividades, es decir, habría que agregar o diversificar. Así lo han hecho otras naciones y es necesario que el INDH genere nuevos enfoques de acuerdo con la realidad país de Chile como también, replicando algunas buenas prácticas de sus pares iberoamericanos.

Palabras clave: Grupos vulnerables. Instituciones Nacionales de Derechos Humanos. Principios de París. Instituto Nacional de Derechos Humanos. Defensor del Pueblo. Iberoamérica.

\footnotetext{
** Doctor en Derecho y Máster en Gobernanza y Derechos Humanos por la Universidad Autónoma de Madrid; Magíster en Docencia Universitaria y Licenciado en Ciencias Jurídicas por la Universidad Autónoma de Chile. Profesor de Derecho Constitucional Universidad Autónoma de Chile e investigador responsable del proyecto Fondecyt de Postdoctorado $N^{\circ} 3200477$. Dirección postal: Avenida Pedro de Valdivia 425, Providencia, Santiago de Chile. Correo de contacto: juanpablo.diaz@uautonoma.cl.

E-mail: jpdiazfuenzalida@gmail.com.

Recebido em 21/10/2020

Aprovado em 01/03/2021
} 


\section{Abstract}

This article studies the National Institute of Human Rights (NIHR) of Chile in its activity of promotion and protection of human rights, specifically in the coherence of focusing on certain vulnerable groups, regarding its 10 years of existence. The hypothesis that guides the research is that the legal figures for the promotion and protection of human rights (originated by the Paris Principles or in application of these) should consider strategies to make their work more effective, being able to focus on the most destitute. For the exercise of verification and generation of reflections, the dogmatic method is used in relation to the specialized doctrine on vulnerable groups. In addition, with the empirical method, the focus of special protection by national human rights institutions in Ibero-America is reviewed, being able to generate common points and relevant differences that serve as good practices. It highlights as a conclusion that the special protection groups that the NHRI has focused on are consistent with the doctrine and experience of the other ombudsmen, but that, nevertheless, other communities should be considered, that is, they should be added or diversified. This has been done by other nations and it is necessary for the NIHR to generate new approaches in accordance with the reality of the country of Chile as well as replicating some good practices of its Latin American counterparts.

Keywords: Vulnerable groups. National Human Rights Institutions. National Institute of Human Rights. Paris principles. Ombudsman. Ibero-America.

\section{Introducción}

Los derechos humanos, no sólo necesitan ser reconocidos, sino que también es menester que se establezcan garantías para que sean efectivos en la práctica. Es por ello por lo que en los años noventa surgen los denominados "Principios de París", que han servido de instrumento fundamental para la constitución de las Instituciones Nacionales de Derechos Humanos. ${ }^{1}$ En efecto, dichos principios, han sido adoptados por la Comisión de Derechos Humanos de las Naciones Unidas (ONU), en concreto, con la Resolución 1992/54, de 1992, que luego fue reafirmada por la Resolución 48/134, de 1993, de la Asamblea General. ${ }^{2}$ En concreto, dicen relación con una serie de criterios a seguir para estatuir instituciones de promoción y protección de los derechos humanos. Y, en aquellos países donde hubiese figuras jurídicas similares, se han reconocido por Naciones Unidas como figuras equivalentes a las Defensorías del Pueblo (Ombudsman). Ello, porque tienen en común, que su mandato abarca la protección y promoción de los derechos humanos y de las libertades fundamentales, ${ }^{3}$ independiente de su denominación, estructura o modos de actuación. Ello nos va dando luces de la naturaleza, relevancia y atribuciones de la figura jurídica objeto de estudio en Chile y en Iberoamérica, especialmente en su rol de promoción y protección de los derechos humanos.

Así, Chile no queda ajeno al proceso, aunque varios años después de los mencionados Principios de París, creando al Instituto Nacional de Derechos Humanos (en adelante INDH) de acuerdo con la ley 20.405 de 2009. Dicha ley consagra que el Instituto tiene por objeto la promoción y protección de los derechos humanos de las personas que habiten en el territorio de Chile, establecidos en las normas constitucionales y legales; en los tratados internacionales suscritos y ratificados por Chile y que se encuentran vigentes, así

\footnotetext{
GÓNZALEZ PÉREZ, Luis Raúl. El sistema no-jurisdiccional de protección de los derechos humanos en México. Revista Ius, Puebla, México, v. 5, n. 28, pp. 99-122. 2011.

2 NACIONES UNIDAS. A/RES/48/134 el 20 de diciembre de 1993, Instituciones nacionales de promoción y protección de los derechos humanos. Disponible en: https://www.oas.org/dil/esp/Res_48-134_UN.pdf Acceso: 01 marzo 2021.

3 COMISIÓN EUROPEA PARA LA DEMOCRACIA. Principios sobre la protección y la promoción de la institución del Defensor del Pueblo (Los Principios de Venecia). Disponible en: https://www.defensordelpueblo.es/wp-content/uploads/2019/04/ Principios-de-Venecia-esp-versi\%C3\%B3n-29-03-19-1.pdf Acceso: 01 marzo 2021.
} 
como los emanados de los principios generales del derecho reconocidos por la comunidad internacional. ${ }^{4}$ Es en cierta manera dar mayor efectividad a la aplicación del bloque de constitucionalidad chileno, que considera normas constitucionales e internacionales que hace suya, ${ }^{5}$ de acuerdo con el artículo 5 de la Carta Fundamental. ${ }^{6}$

En efecto, la ley citada específica "habitantes" de manera que puede ser cualquier persona natural quien puede ser protegida, pero por la actividad defensorial limitada del INDH debe enfocarse en grupos especiales, ayudando a los más vulnerables en relación con sus derechos humanos. Ello es justificable pues la vulnerabilidad genera a quien la padece, entre otras cosas, una situación de desventaja frente al ejercicio pleno de sus derechos y libertades, ya sea por desconocimiento de los mismos o que sean sólo derechos en lo formal por no poder ponerlos en ejercicio. ${ }^{7}$ Haciendo un símil con Naciones Unidas, en casos de desastres humanitarios, se centra especialmente en las poblaciones vulnerables, particularmente en niños, refugiados y desplazados. ${ }^{8}$ En ese sentido, estas instituciones, y, particularmente el INDH debe preocuparse de la promoción y protección de todos los habitantes, siendo apropiado que pueda enfocarse en los más desprotegidos, aunque sin descuidar sus competencias generales en relación con la población en su conjunto.

De ahí la necesidad de analizar aspectos relativos a la vulnerabilidad en relación con las instituciones nacionales de derechos humanos, dado que es un factor determinante en la decisión de dar mayor o menor importancia a propósito de la promoción y protección de sus derechos. En efecto, se entiende por vulnerable a "la población que no puede atender necesidades por sus propios medios, por lo cual necesita ayuda externa para salir adelante"." También, hay grados en la intensidad de la vulnerabilidad. Los aspectos sociales, como la clase, género, etnia o preferencias sexuales, o los biológicos como el sexo y edad, y, las condiciones estructurales del entorno como la cultura, la política y la economía, son elementos que determinan el grado de vulnerabilidad de un grupo, de un individuo o de una sociedad. ${ }^{10}$

Lo anterior tiene efectos prácticos, incluso cuantificables, por lo que es menester profundizar sobre la materia. Como se decía, la repercusión es latente y evidenciable, lo que nos puede dar luces sobre las actuaciones de las instituciones. Así, por ejemplo, en el informe anual 2020, el INDH afirmó, a propósito de la crisis sanitaria del Covid-19 en el ámbito laboral que, "la pandemia afecta a todos, pero de diferente manera", enfocándose como grupo vulnerable en las mujeres, jóvenes, niñas, niños, adolescentes, migrantes, trabajadoras de casa particular, personas con discapacidad y pueblos indígenas. ${ }^{11}$ Ello no quiere decir que no se haya

\footnotetext{
4 CHILE. Ley 20.405, de 10 de diciembre de 2009, del Instituto Nacional de Derechos Humanos, última modificación de 25 de abril de 2019, Ley 21.154. Disponible en: https://www.bcn.cl/leychile/navegar?idNorma=1008867 Acceso: 16 octubre 2020.

5 DÍAZ FUENZALIDA, Juan Pablo. ¿Son parte del bloque de constitucionalidad los principales tratados internacionales de derechos humanos de la ONU en Chile? Del texto positivo a la aplicación en tribunales de justicia. Revista Brasileira de Políticas Públicas, Brasilia, Brasil, v. 9. n. 1, pp. 152-171. 2019.

6 CHILE. Decreto 100, de 22 de septiembre de 2005, que Fija el texto refundido, coordinado y sistematizado de la Constitución Política de la República de Chile (última versión 23 de diciembre de 2020). Disponible en: https://www.bcn.cl/leychile/ navegar?idNorma=242302 Acceso: 17 de febrero de 2020.

ESPINOSA MUNGUÍA, María Socorro, CALZONCIT, José Luis y VALDEZ HUERTA, María del Rosario. Los Trabajadores Sociales ¿Un grupo vulnerable? En: ACEVEDO ALEMÁN, Jesús, TRUJILLO PÉREZ, María de los Ángeles y LÓPEZ SAUCEDO, María de la Luz (coordinadores). La problemática de los grupos vulnerables: Visiones de la realidad, México: Universidad Autónoma de Coahuila, 2012, pp. 10-33.

8 NACIONES UNIDAS. Protección de los más vulnerables, 2013. Disponible en: http://www.un.org/es/humanitarian/overview/protection.shtml Acceso: 18 agosto 2016.

9 ESPINOSA MUNGUÍA, María Socorro, CALZONCIT, José Luis y VALDEZ HUERTA, María del Rosario. Los Trabajadores Sociales ¿Un grupo vulnerable? En: ACEVEDO ALEMÁN, Jesús, TRUJILLO PÉREZ, María de los Ángeles y LÓPEZ SAUCEDO, María de la Luz (coordinadores). La problemática de los grupos vulnerables: Visiones de la realidad, México: Universidad Autónoma de Coahuila, 2012, pp. 10-33.

10 ESPINOSA MUNGUÍA, María Socorro, CALZONCIT, José Luis y VALDEZ HUERTA, María del Rosario. Los Trabajadores Sociales ¿Un grupo vulnerable? En: ACEVEDO ALEMÁN, Jesús, TRUJILLO PÉREZ, María de los Ángeles y LÓPEZ SAUCEDO, María de la Luz (coordinadores). La problemática de los grupos vulnerables: Visiones de la realidad, México: Universidad Autónoma de Coahuila, 2012, pp. 10-33.

11 CHILE. Instituto Nacional de Derechos Humanos. Informe Anual. Situación de los derechos humanos en Chile 2020. Disponible en: https://ia2020.indh.cl/informe/INFORME-INDH-2020.pdf Acceso: 16 febrero 2021, pp. 140-151.
} 
preocupado a nivel general de las demás personas y de algún otro grupo vulnerable, pero es un antecedente a considerar que repercute en las actuaciones defensoriales, ya sea evidenciando problemáticas de derechos humanos o en las respectivas recomendaciones.

A mayor abundamiento, ser considerado o no grupo vulnerable por una institución de derechos humanos tiene consecuencias inclusive en actuaciones judiciales de promoción y protección. En relación con la figura jurídica en estudio, el INDH, de acuerdo con la información del portal del poder judicial de Chile, en el año 2016 presentó y actuó hasta la Excelentísima Corte Suprema en materia de recurso de protección de garantías constitucionales en: uno en favor de una persona con discapacidad visual por una eventual discriminación; ${ }^{12}$ uno en favor de extranjeros que querían celebrar un día patrio en Chile; ${ }^{13}$ y, cuatro en favor de personas privadas de libertad para que pudieran ejercer derechos de sufragio. ${ }^{14} \mathrm{Si}$ bien, puede estimarse que son escasas las actuaciones en tribunales de justicia, lo cierto es que es la regla general en instituciones donde prevalece la auctoritas y no la potestas (a excepción de la Defensoría del Pueblo de Colombia). ${ }^{15}$ Sin embargo, queda en evidencia los efectos concretos de ser o no considerado vulnerable en la promoción y protección de los derechos, pues determinará la actuación o no de la institución. Los recursos presentados fueron justamente en favor de grupos en situación de vulnerabilidad.

Consecuencia de lo anterior es que la problemática se va evidenciando, es decir, si ya se es vulnerable, pero no se es considerado así para los efectos de las instituciones de derechos humanos, se profundiza aún más en dicha situación de fragilidad. Con ello, se genera una hipótesis afirmativa, ${ }^{16}$ en el sentido que, las figuras jurídicas de promoción y protección de los derechos humanos deben considerar estrategias para dar mayor efectividad, especialmente en relación los más desamparados. Para ello debe tener presente a la doctrina especializada sobre grupos vulnerables y contrastarse con instituciones afines para tomar las buenas prácticas de sus pares en distintas latitudes. Así, la investigación contemplará para su desarrollo el método dogmático, en relación con la doctrina especializada sobre grupos vulnerables. ${ }^{17}$ Además, el método empírico, particularmente para revisar el enfoque de especial protección por parte de las instituciones nacionales de derechos humanos. ${ }^{18}$

Con todo, para cumplir con el objeto de la presente investigación, contrastar la hipótesis y utilizar los métodos señalados, en adelante, revisaremos los grupos que más se ha enfocado el INDH, considerando doctrina para determinar la coherencia de estimarlos para su especial protección. Posteriormente, se revisarán algunos casos distintos de los que se ha hecho cargo otras instituciones nacionales de derechos humanos iberoamericanas, también aplicando doctrina. Ello nos dará luces para reflexionar sobre las estrategias de promoción y promoción de los derechos humanos, concretamente en quién o quiénes son y/o deben ser considerados vulnerables.

\footnotetext{
12 CHILE. Corte Suprema. Rol 27697-2016. Disponible en el expediente electrónico ingresando el rol indicado en: https://suprema.pjud.cl/SITSUPPORWEB/InicioAplicacion.do Acceso: 16 de febrero de 2021.

13 CHILE. Corte Suprema. Rol 68679-2016. Disponible en el expediente electrónico ingresando el rol indicado en: https://suprema.pjud.cl/SITSUPPORWEB/InicioAplicacion.do Acceso: 16 de febrero de 2021.

14 CHILE. Corte Suprema. Roles 87743-2016, 87748-2016, 87876-2016, 92816-2016. Disponible en el expediente electrónico ingresando el rol indicado en: https://suprema.pjud.cl/SITSUPPORWEB/InicioAplicacion.do Acceso: 16 de febrero de 2021.

15 DÍAZ FUENZALIDA, Juan Pablo. Un aporte a la protección de los derechos humanos en Latinoamérica: la actividad del Ombudsman Criollo en tribunales de justicia. Revista Brasileira de Políticas Públicas, Brasilia, Brasil, v. 9. n. 2, 2019 , pp. 493-511.

16 HERNÁNDEZ SAMPIERI, Roberto, FERNÁNDEZ COLLADO, Carlos y BAPTISTA LUCIO, Pilar. Metodología de la Investigación, sexta edición. Editorial Mcgraw-Hill: México, 2013.

17 SÁNCHEZ ZORRILLA, Manuel. La metodología en la investigación jurídica: características peculiares y pautas generales para investigar en el derecho. Revista Telemática de Filosofía del Derecho, n. 14, pp. 317-358. 2011.

18 VILLABELLA ARMENGOL, Carlos Manuel. Los métodos en la investigación jurídica. Algunas precisiones. En: GODÍNEZ MÉNDEZ, Wendy y GARCÍA PEÑA, José (coordinadores). Metodologías: enseñanza e investigación jurídicas, 40 años de vida académica. Homenaje a Jorge Witker. México, 2015, pp. 921-953.
} 


\section{Grupos considerados por el INDH}

El INDH ha puesto énfasis en algunos grupos específicos, generando en sus 10 años de historita una base documental al efecto. ${ }^{19}$ Así, clasifica la información en los siguientes colectivos: diversidades sexuales, mujeres, niños, niñas y adolescentes, adultos mayores, personas con discapacidad, migrantes, privados de libertad, refugiados y pueblos indígenas. Por un asunto de mejor comprensión, se seguirá en este apartado dicho orden:

\subsection{Diversidades sexuales}

En general, este grupo de especial protección se genera por la ausencia o poco reconocimiento y/o discriminación hacía este colectivo. La problemática se da entonces con la imposición del orden de la mayoría, que niega o no toma en consideración la diferencia y no reconoce la complejidad de las relaciones humanas. En efecto, a pesar de los avances que ha habido en la materia, incluso en países desarrollados donde existe legislación que protege a las personas con distinta orientación sexual o de identidad de género, no siempre es así, guiándose hacía modelos conservadores o donde la propia sociedad, valga la redundancia, es más conservadora. En cuanto a los países en desarrollo, hay países que han avanzado, pero muchos de ellos siguen con vacíos o escaso reconocimiento de la diversidad sexual y existe en ocasiones la idea de eliminación de la diferencia. ${ }^{20}$

\subsection{Mujeres}

En ocasiones los embarazos hacen vulnerables a las mujeres. Particularmente en el caso de las adolescentes, es un factor que frecuentemente es determinante para que deserten de la escuela, que produce grandes riesgos para la salud materno-infantil y que es un mecanismo que conlleva a la transmisión de la pobreza intergeneracional. ${ }^{21}$

Un subgrupo vulnerable son las mujeres indígenas. Es un asunto muy particular, donde el debate gira entorno a quienes defienden la multiculturalidad, prevaleciendo las costumbres del pueblo originario (pudiendo incluso vulnerarse derechos de mujeres indígenas) contra los que consideran que los derechos son individuales prevaleciendo el derecho de las mujeres. En un estudio que se hizo en México respecto de mujeres indígenas, se evidencia que ellas viven en una situación donde sus derechos son constantemente vulnerados. El derecho a una vida libre de violencia, poder asistir a la escuela, decidir si salir o no, e incluso tener propiedades son derechos que son frecuentemente lesionados. Así, dichas personas sufren el riesgo de no ejercer plenamente sus derechos humanos, teniendo derechos solo a nivel formal, ya que en los hechos no tienen las condiciones necesarias para su ejercicio. ${ }^{22}$ Otro subgrupo lo podemos encontrar en lo que se ha denominado feminismo negro, que busca igualdad añadiendo la superación de desigualdades añadiendo el factor de discriminación por raza. ${ }^{23}$ Es decir, puede agregarse otra vulnerabilidad lo que puede profundizar aún más la situación de desigualdad.

\footnotetext{
19 CHILE. Instituto Nacional de Derechos Humanos. Género y Grupos de Protección. Disponible en: https://bibliotecadigital. indh.cl/handle/123456789/4 Acceso: 16 octubre 2020.

20 TORO-ALFONSO, José. El Estado Actual de la Investigación Sobre la Discriminación Sexual. Terapia psicológica, Santiago, Chile, v. 30, n. 2, 2012, pp. 71-76.

21 REYES, David de Jesús, AMADOR CORREDOR, Sandra R. y CHÁVEZ VALERIO, Cecilia G. Adolescencia y embarazo: supuestos e implicaciones en su estudio como grupo vulnerable. En: ACEVEDO ALEMÁN, Jesús, TRUJILLO PÉREZ, María de los Ángeles y LÓPEZ SAUCEDO, María de la Luz (coordinadores). La problemática de los grupos vulnerables: Visiones de la realidad, México, 2012, pp. 219-230.

22 ROSAS VARGAS, Roció, JASSO MARTÍNEZ, Ivy Jacaranda y HUACUZ ELÍAS, Guadalupe. Mujeres indígenas y violencia de género en Michoacán. En: ACEVEDO ALEMÁN, Jesús, TRUJILLO PÉREZ, María de los Ángeles y LÓPEZ SAUCEDO, María de la Luz (coordinadores). La problemática de los grupos vulnerables: Visiones de la realidad, México, 2012, pp. 150-163.

23 GARCEZ CALIL, Mário Lúcio y MARKMAN, Debora. Direito, raça e gênero: elementos para a construção de uma teoría feminista do direito adequada ao feminismo negro. Revista Brasileira de Políticas Públicas, Brasilia, Brasil, v. 10. n. 2, 2020, pp. $173-195$.
} 
No necesariamente vulnerabilidad, pero si una desventaja para las mujeres respeto a los hombres es la creación histórica del Derecho, que ha sido androcentrista. En efecto, como ha señalado el Doctor Honoris Causa, Catedrático de Derecho Constitucional, Carlos de Cabo que, la mujer no era precisamente sujeto de derecho, de ahí que afirma que el feminismo jurídico implica "un amplio programa de revisión del Derecho en cuanto configuración históricamente androcentrista y, por tanto, de sus categorias centrales empezando por la fundamental de sujeto de Derecho, modelo de cómo su plenitud solo ha sido masculina". ${ }^{24}$ Desde ese paradigma se ha creado la modernidad y se ha desarrollado la mayoría de la normativa.

\subsection{Niños, niñas y adolescentes}

Este grupo se puede ver afectado por diversas razones. De hecho, en general hay acuerdo, que llega a materializarse en normativa que los derechos de los niños deben ser garantizados con prioridad, incluyendo la preferencia por la formulación y ejecución de políticas sociales y el destino de los recursos públicos. La realización de estos derechos depende de la articulación de la familia, el Estado y la sociedad, exigiendo una acción diferenciada por parte del Estado ante casos de mayor vulnerabilidad. ${ }^{25}$ Así, además de los elementos clásicos, hoy en día se agrega como factor de vulnerabilidad a los trastornos alimenticios en los niños. El sobrepeso, obesidad, bulimia o anorexia infantil configuran un colectivo de vulnerabilidad, la que se presenta en un contexto de desigualdad, pues afecta en su mayoría a los grupos con menos recursos económicos. ${ }^{26}$ Para el caso de la obesidad, ya hay algunos que hablan de una verdadera epidemia, que se ha extendido hasta los grupos de población más jóvenes, afectando a una gran cantidad de niños y adolescentes, por lo que se ha convertido en uno de los principales problemas de salud pública del siglo XXI. ${ }^{27}$

De manera que los trastornos alimenticios producen efectos nocivos a la persona, no sólo a la salud física, sino que también a la psíquica, lo que se acentúa particularmente en los niños y adolescentes porque pueden ser afectados con la discriminación y con el denominado bullying. En efecto, la obesidad infantil, además de las consecuencias hacía la salud, trae consigo efectos psicológicas como bajo nivel de autoestima con cuadros de tristeza, soledad, nerviosismo, imposición de etiquetas, experiencias de estigmatización y prejuicios, discriminación escolar y social, burlas relacionadas a su peso, bromas y comentarios ofensivos por parte de sus compañeros o de los mismos miembros de su familia, provocando a través de los años, una mayor probabilidad de riesgo para el consumo de drogas, cigarrillos o alcohol. Además, estudios han comprobado la asociación de la obesidad en los niños con discriminación escolar y discriminación social, fatiga fácil, ${ }^{28}$ entre otros puntos negativos.

La discriminación debido al peso corporal de una persona comienza en la edad preescolar. Los niños se burlan de sus compañeros obesos, a quienes eligen menos como compañía para jugar. Ha habido estudios

${ }^{24}$ ESQUEMBRE CERDÁ, María del Mar. Feminismo y constitucionalismo crítico. En: GARCÍA HERRERA, Miguel Ángel, ASENSI SABATER, José y BALAGUER CALLEJÓN, Francisco (directores) Constitucionalismo Crítico: Liber amicorum Carlos de Cabo Martín, Tirant lo Blanch, España, v. 1, 2016, p. 391-402.

25 STRAPASSON JAMBERSI, Karoline y GONÇALVEZ DE OLIVEIRA, Antonio. Orçamento para os direitos das crianças e adolescentes em Curitiba: plano e execução. Revista Brasileira de Políticas Públicas, Brasilia, Brasil, v. 10. n. 1, 2020 , pp. $223-234$.

26 CABELlO GARZA, Martha Leticia, ÁvILA ORTíZ, María Natividad, GARZA MONTOYA, Beatriz Gabriela. Obesidad: Los problemas de los grupos vulnerables. En: ACEVEDO ALEMÁN, Jesús, TRUJILLO PÉREZ, María de los Ángeles y LÓPEZ SAUCEDO, María de la Luz (coordinadores). La problemática de los grupos vulnerables: Visiones de la realidad, México, 2012, pp. 73-88.

27 ONOFRE RODRÍGEZ, Dora Julia y CABELLO GARZA, Martha Leticia. Vulnerabilidad social en Adolescentes con Síndrome Metabólico. "Un problema mundial de índole social". En: ACEVEDO ALEMÁN, Jesús, TRUJILLO PÉREZ, María de los Ángeles y LÓPEZ SAUCEDO, María de la Luz (coordinadores). La problemática de los grupos vulnerables: Visiones de la realidad, México, 2012, pp. 164-171.

28 CABELlO GARZA, Martha Leticia, ÁVILA ORTÍZ, María Natividad, GARZA MONTOYA, Beatriz Gabriela. Obesidad: Los problemas de los grupos vulnerables. En: ACEVEDO ALEMÁN, Jesús, TRUJILLO PÉREZ, María de los Ángeles y LÓPEZ SAUCEDO, María de la Luz (coordinadores). La problemática de los grupos vulnerables: Visiones de la realidad, México, 2012, pp. 73-88. 
que calculan que por lo menos treinta por ciento de las niñas, y veinticuatro por ciento de los niños con sobrepeso han dicho que sus compañeros se burlan de ellos en la escuela. Los adolescentes con sobrepeso son quienes con mayor frecuencia sufren de las burlas debido a su peso. Además, la tendencia a estigmatizar continúa durante la preparatoria y la universidad, donde a los estudiantes obesos se les considera como faltos de moderación, flojos, y se les excluye de las actividades sociales con frecuencia. ${ }^{29}$

Otro grupo vulnerable son los jóvenes, pero más aún los marginales, quienes si no logran superar ciertos obstáculos quedan fuera de la educación formal. Es decir, salvando ciertas excepciones, quedan "al margen" de una serie de oportunidades, derechos y servicios básicos. ${ }^{30}$ En efecto, hay autores, como Bourdieu, Granja, Maimone y Edelstein que consideran que los grados de escolaridad serían un medio por virtud del cual se accede a bienes que anteriormente se heredaban a través los títulos nobiliarios, ${ }^{31}$ por lo que dejar fuera a determinados grupo de jóvenes sería equivalente de mantener dicho régimen histórico.

Otro subgrupo lo componen a quienes se les ha denominado niños, niñas y adolescentes en la calle. Son aquellos cuya supervivencia depende o está en riesgo de depender de su propia actividad en la propia vía pública, que los pone en una situación de peligro respecto de su integridad física y psíquica. En general, tienen precarias condiciones de alimentación, recreación, salubridad, baja escolaridad o carecen de ella, en ocasiones sobreviven gracias a una red callejera, no obstante tener familia. ${ }^{32}$

\subsection{Personas adultas mayores}

Las personas de la tercera edad suelen también ser un sector vulnerable. En general, más o menos desde los setenta años comienza a haber cambios significativos que tipifican la vida de adultos mayores, como el llamado nido vacío, el retiro o jubilación, la viudez, convertirse en abuelo o abuela, cambio de vivienda, entre otros, los que dan paso a la llamada tercera edad. ${ }^{33}$

Entre las diversas formas de discriminación que afectan a las personas de este grupo y a su familia, es posible destacar, entre otras, las siguientes situaciones: ${ }^{34}$

- Reclamaciones en materia de pensiones.

- Solicitud de beneficios de ley.

29 CABELlO GARZA, Martha Leticia, ÁVILA ORTíZ, María Natividad, GARZA MONTOYA, Beatriz Gabriela. Obesidad: Los problemas de los grupos vulnerables. En: ACEVEDO ALEMÁN, Jesús, TRUJILLO PÉREZ, María de los Ángeles y LÓPEZ SAUCEDO, María de la Luz (coordinadores). La problemática de los grupos vulnerables: Visiones de la realidad, México, 2012, pp. 73-88.

30 LOSANO MALDONADO, María Cecilia y GARCÍA HORTA, José Baltazar. El joven marginal y la educación formal. Reflexiones en torno a la inclusión y la equidad educativa. En: ACEVEDO ALEMÁN, Jesús, TRUJILLO PÉREZ, María de los Ángeles y LÓPEZ SAUCEDO, María de la Luz (coordinadores). La problemática de los grupos vulnerables: Visiones de la realidad, México, 2012, pp. 89-104.

31 LOSANO MALDONADO, María Cecilia y GARCÍA HORTA, José Baltazar. El joven marginal y la educación formal. Reflexiones en torno a la inclusión y la equidad educativa. En: ACEVEDO ALEMÁN, Jesús, TRUJILLO PÉREZ, María de los Ángeles y LÓPEZ SAUCEDO, María de la Luz (coordinadores). La problemática de los grupos vulnerables: Visiones de la realidad, México, 2012, pp. 89-104.

32 JASSO OYERVIDES, Martha Virginia y LÓPEZ SAUCEDO, María de la Luz. La calidad de vida de los niños en la calle. En: ACEVEDO ALEMÁN, Jesús, TRUJILLO PÉREZ, María de los Ángeles y LÓPEZ SAUCEDO, María de la Luz (coordinadores). La problemática de los grupos vulnerables: Visiones de la realidad, México, 2012, pp. 172-190.

33 ARRIAGA BUENO, Reyna Alicia y CABALLERO RIVACOBA, María Teresa. La salud y el ingreso como indicadores de la calidad de vida del adulto mayor. Una reflexión desde el trabajo social. En: ACEVEDO ALEMÁN, Jesús, TRUJILLO PÉREZ, María de los Ángeles y LÓPEZ SAUCEDO, María de la Luz (coordinadores). La problemática de los grupos vulnerables: Visiones de la realidad, México, 2012, pp. 231-245.

34 ACEVEDO ALEMÁN, Jesús, TRUjILLO PÉREZ, María de los Ángeles y LÓPEZ SAUCEDO, María de la Luz. Los Adultos Mayores vistos por sí mismos: Percepciones de su persona y calidad de vida [Notas iníciales]. En: ACEVEDO ALEMÁN, Jesús, TRUJILLO PÉREZ, María de los Ángeles y LÓPEZ SAUCEDO, María de la Luz (coordinadores). La problemática de los grupos vulnerables: Visiones de la realidad, México, 2012, pp. 289-295. 
- Atención médica deficiente.

- Ejercicio indebido de la función pública.

- Negativa de solicitudes de atención médica.

- Dilación en procedimientos administrativos.

- Maltrato en asilos.

- Irregularidades en la integración de averiguaciones previas.

- Despido en razón solo a la edad.

- Lanzamientos de propiedades.

- Negativa a dar empleo por edad.

Uno de los factores que hace vulnerable a la tercera edad es la salud o, mejor dicho, la ausencia o lo precaria que pueda ser. En efecto, a medida que se envejece aumentan el riesgo de enfermedades y discapacidades, ya sea por ser más frecuentes, crónicas, de difícil o inclusive inexistencia recuperación. En general, las enfermedades diagnosticadas en los adultos mayores no son curables, las que si no se tratan oportunamente provocan complicaciones y secuelas que menoscaban en mayor o menor medida su independencia. En todo caso, a pesar de que los adultos mayores mantengan una capacidad funcional, es innegable que el grado de autonomía disminuye con la edad. ${ }^{35}$

No obstante, algunas personas de la tercera edad serán más vulnerables que otras, y es ahí donde debe haber mayor preocupación. En efecto, se debe considerar la condición económica, no es lo mismo un jubilado recibiendo el mínimo posible que uno que reciba cinco veces o más. Tampoco es idéntica la situación de un adulto mayor con una condición saludable que otro que tenga enfermedades crónicas. ${ }^{36}$ Otro caso es el de aquellos adultos mayores que tengan que valerse de ellos y también de su cónyuge, incluso de hijos y nietos, que se sume también ser jefe de hogar, o alguno que esté solo a otro que tenga el apoyo de un grupo familiar.

\subsection{Persona con discapacitad}

Según la Real Academia Española, discapacitado, se dice de una persona que padece de una disminución física, sensorial o psíquica que la incapacita total o parcialmente para el trabajo o para otras tareas ordinarias de la vida. ${ }^{37}$ Asimismo, hay factores externos que agravan su condición, cual es la falta o insuficientes políticas inclusivas a este colectivo. En ese sentido, no es casualidad que cuarenta de los ciento quince millones de niños que están fuera de la escolaridad en el mundo tengan alguna discapacidad. No sólo el Estado es participe de su vulnerabilidad, sino que la sociedad también lo es, pues estas personas suelen ser discriminadas o excluidas. ${ }^{38}$ De manera que, aquella condición diferente, como también la ausencia o poca integración en la sociedad y en un Estado es lo que los hace vulnerables o profundiza en ésta.

A mayor abundamiento, se ha dicho respecto a este colectivo que es uno de los que se encuentra en

35 OYERVIDES VALDÉS, Lourdes. Un México Maduro y Enfermo Bucalmente. En: ACEVEDO ALEMÁN, Jesús, TRUJILLO PÉREZ, María de los Ángeles y LÓPEZ SAUCEDO, María de la Luz (coordinadores). La problemática de los grupos vulnerables: Visiones de la realidad, México, 2012, pp. 265-288.

36 ARriagA BUENO, Reyna Alicia y CABALLERO RIVACOBA, María Teresa. La salud y el ingreso como indicadores de la calidad de vida del adulto mayor. Una reflexión desde el trabajo social. En: ACEVEDO ALEMÁN, Jesús, TRUJILLO PÉREZ, María de los Ángeles y LÓPEZ SAUCEDO, María de la Luz (coordinadores). La problemática de los grupos vulnerables: Visiones de la realidad, México, 2012, pp. 231-245.

37 REAL ACADEMIA ESPAÑOLA. Discapacitado. Disponible en: http://dle.rae.es/?id=DrrzNuK Acceso: 16 octubre 2020.

38 CROSSO, Camila. El Derecho a la Educación de Personas con Discapacidad: impulsando el concepto de Educación Inclusiva. Revista Latinoamericana de Educación Inclusiva, Santiago, Chile, v. 4, n. 2, 2010, pp. 79-95. 
mayor grado de riesgo. En efecto, el doctor Miguel Ángel Vite ha manifestado que "la vulnerabilidad es la fase previa de ruptura de los lazos sociales, sobre todo cuando no existen protecciones sociales gestionadas por el sistema estatal de bienestar. Sin embargo, existen grupos sociales que caen más rápidamente en la fase de ruptura de los lazos sociales, lo que desde un punto de vista sociológico se ha llamado desafiliación, como es el caso de las personas que sufren algún tipo de discapacidad" ${ }^{39}$

\subsection{Personas migrantes y refugiadas}

Una persona inmigrante internacional, más conocida como extranjero, es vulnerable, aunque también puede serlo o no en su país de origen. El asunto es considerar los factores de vulnerabilidad respecto a su condición de extranjero y su relación con otra sociedad y con el nuevo Estado al que emigra. El primer hecho de vulnerabilidad es aquella distinción de extranjero con nacional, que proviene de la sociedad, y, la base común para hacer dicha separación es la connotación legal derivada en la mayor parte de los países en su respectiva Constitución, donde se define usualmente quien es nacional y quién no. Dicha distinción en muchas ocasiones ha servido de fundamento para que las leyes puedan justificar un trato distinto, incluso de inferioridad con los extranjeros respecto de los nacionales. Dicha posición de superioridad genera riesgos de vulnerabilidad, ya sea de facto o de iure, como si el nacional le dijera al inmigrante, "yo tengo más derechos que tú, mientras estés en mi tierra". ${ }^{40}$

Además de lo anterior, en general a los inmigrantes les afecta con mayor énfasis determinados acontecimientos. Por ejemplo, cuando aumenta el desempleo el trabajador extranjero pierde biografía ocupacional, como también que mantiene o baja sus salarios respecto de los empleados nacionales. En muchas latitudes también los trabajos temporales, que en general son por los que suelen ser contratados los extranjeros, hace que sean más vulnerables. Estos trabajos son además en su mayoría menos calificados que los nacionales y por tanto con menor remuneración. Asimismo, suele afectarles el tiempo de residencia, las características personales, la discriminación ya sea étnica y por otras circunstancias como pueden ser el lugar de residencia o los aspectos de legalidad residencial y laboral. ${ }^{41}$

En esta área también suele estudiarse a los inmigrantes internos, que se les ha denominado desplazados internos forzados, verdaderos refugiados invisibles en su propia patria. Lo que caracteriza esta situación de vulnerabilidad es la ausencia de Estado de Derecho, sumada a la pérdida de control del territorio por instituciones políticas y de orden público. Ello causa una especie de feudalización de vastas zonas por parte de grupos delictivos y político-militares que aterrorizan a los habitantes. Así se generan verdaderos éxodos de personas, familias y hasta poblaciones, acontecimiento que es más común en zonas rurales, migrando sus residentes a ciudades o a otras regiones en el mismo Estado (por eso son desplazados “internos", migración interna en el Estado). ${ }^{42}$ Aunque la decisión, o, mejor dicho, la necesidad de emigrar puede tener distintas causales. De acuerdo a una definición de desplazados internos se ha señalado que, "son personas o grupos de personas forzadas a escapar o buir de su lugar de residencia habitual, como resultado o para evitar los efectos de un conflicto armado, de situaciones de violencia generalizada, de violaciones a los derechos humanos o de catástrofes naturales o provocadas por el ser humano, y que no han cruzado frontera estatal internacionalmente reconocida". ${ }^{43}$ De manera que ese éxodo intempestivo, necesario, sin planificar, es lo que, entre otras cosas, generará una vulnerabilidad respecto de

\footnotetext{
39 VITE PÉREZ, Miguel Ángel. La discapacidad en México desde la vulnerabilidad social. Polis, México, v. 8, n. 2, 2012, pp. 153173.

40 BUSTAMANTE, Jorge A. La vulnerabilidad de los migrantes internacionales como sujetos de Derechos Humanos, 2017. Disponible en: https://silo.tips/download/documento-sobre-mejores-practicas-relativas-a-trabajadores-migrantes Acceso: 16 octubre 2020.

41 CARRASCO CARPIO, Concepción. La vulnerabilidad laboral de los extranjeros en España. Migraciones Internacionales, Tijuana, México, v. 8, n. 2, 2015, pp. 41-72.

42 MESTRIES, Francis. Los desplazados internos forzados: refugiados invisibles en su propia patria. El Cotidiano, Distrito Federal, México, n. 183, 2014, pp. 17-25.

43 NACIONES UNIDAS. Principios rectores de los desplazamientos internos, 1998. Disponible en: http://www.acnur.es/ PDF/0022_20120416132756.pdf Acceso: 26 agosto 2016.
} 
los mismos nacionales.

En esta área suele también revisarse en específico la trata de personas. Es uno de los delitos que en mayor medida atentan contra los derechos humanos, vulnerando la dignidad de sus víctimas, afectando a familias y comunidades enteras. Es frecuente que la delincuencia organizada sea la que participa en la ejecución de estas atrocidades que se cometen con los seres humanos. En general, la trata dice relación con fines de explotación sexual y/o laboral. ${ }^{44}$ Por todo aquello, y, como los traslados son de extranjeros, es usual que la trata y tráfico de personas sea analizado con asuntos migratorios. Además, la vulnerabilidad de los migrantes afecta a su entorno social, especialmente a sus familiares. Hay estudios que revelan que se generan trastornos como depresión, ansiedad en los cónyuges de migrantes, como también aumento y abuso de drogas y alcohol entre sus hijos. ${ }^{45}$

Para el caso particular chileno, es interesante tener en cuenta que, en un estudio realizado sobre jurisprudencia de los últimos diez años, se ha encontrado que solo en el 10 por cierto de han referido expresamente los tribunales a los tratados internacionales ratificados por Chile y vigentes, ${ }^{46}$ de manera que es una oportunidad y al mismo tiempo un deber de las instituciones nacionales de derechos humanos promover la aplicación de las normas en esta materia.

\subsection{Personas privadas de libertad}

Las personas privadas de libertad son especialmente vulnerables puesto que incluso en las sociedades y Estados donde prevalece el imperio de la ley, en ocasiones tanto el personal de recintos carcelarios como las autoridades del país pueden caer en la tentación de recurrir al uso de fuerza desmedida para alcanzar sus objetivos, ya sean políticos o militares. No sólo puede haber malos tratos o degradantes, sino que hay reclusos que tienen el riesgo de desaparecer. Ahora bien, aunque no haya mala intención de parte de los Estados o del personal penitenciario, en ciertos casos los lugares de detención no cumplen con las condiciones básicas de Derecho Internacional en la materia, que persiguen que el recluso pueda vivir sin que se le vulnere su dignidad humana. Otro aspecto relevante es que son especialmente vulnerables en este colectivo las mujeres y los niños, por ejemplo, una mujer embarazada o con un lactante que esté recluido en un centro penitenciario. ${ }^{47}$

\subsection{Personas indígenas}

Uno de los grupos de especial protección son los indígenas por sus formas particulares de vida, que en general los convierte en vulnerables. Ello porque están algo incomunicados con el Estado o viceversa, como también las propias comunidades autóctonas en su conjunto. Tanto es así, que son consideradas por algunos como una micropolítica al interior de un Estado. ${ }^{48}$ Éste último aspecto, que una comunidad, un colectivo, sea sujeto de protección es algo complejo de entender, debido a la tradición continental de derecho o incluso

\footnotetext{
44 MÉXICO. Comisión Nacional de los Derechos Humanos. Diagnóstico de las Condiciones de Vulnerabilidad que Propician la Trata de Personas en México, 2009. Disponible en: http://www.iberopuebla.mx/micrositios/observatorioviolencia/bibliotecavirtual/genero_\%20y_violencia/2diagnostico_trata_de_personas_ceidas_cndh.pdf Acceso: 29 agosto 2016.

45 SALGADO DE SNYNER, V. Nelly, GONZÁLEZ VÁSQUEZ, Tonatiuh, BOJORQUEZ CHAPELA, Letza, INFANTE XIBILE, César. Vulnerabilidad social, salud y migración México-Estados Unidos. Salud Pública de México, Cuernavaca, México, v. 49, pp. 8-10. 2007.

46 DÍAZ TOLOSA, Regina Ingrid. Expulsion of aliens: the application of International Law by Chilean superior courts. Revista de Direito Internacional, Brasilia, Brasil, v. 17, n. 2, pp. 308-330. 2020.

47 COMITÉ INTERNACIONAL DE LA CRUZ ROJA. Privados de libertad, 2003, Ginebra. Disponible en: https://www.icrc. org/spa/assets/files/other/icrc_003_0685.pdf Acceso: 16 octubre 2020.

48 ROCCATTI, Mireille. Los derechos de los indígenas en la legislación mexicana e investigación de violaciones a Derechos Humanos en comunidades indígenas. En: UNIVERSIDAD ALCALÁ DE HENARES. El Fortalecimiento del Ombudsman Iberoamericano. 1999.
} 
romanista ${ }^{49}$ sobre todo en materia de derechos humanos venían siendo fruto de una modernidad antropocéntrica e individualista. Lo anterior, dado que los derechos fueron originados de las revoluciones liberales del siglo XVIII que ponían acento en las libertades del individuo frente al Estado. ${ }^{50}$ Sin embargo, la Corte Interamericana de Derechos Humanos ya ha reconocido a los pueblos originarios, concediéndoles acciones y recursos, por tanto, verdaderos sujetos de derecho. ${ }^{51}$

\section{Enfoque en otros grupos vulnerables por diversas instituciones nacionales de derechos humanos o figuras afines}

Ya se han revisado las categorías en las que ha clasificado su material bibliográfico el INDH. De manera que más adelante se evidenciarán enfoques de especial protección a otros grupos vulnerables de acuerdo con la experiencia iberoamericana integrando doctrina especializada al efecto. Ello no quiere decir que el INDH nunca se haya preocupado con alguna medida, sino que son categorías en las que las naciones que se tomarán como ejemplo han dado mayor significación. En la medida que vaya avanzándose en la exposición, se podrá ir reflexionando si estos colectivos o personas en situaciones similares podrían ser o no de especial protección por parte del INDH.

\subsection{Campesinos}

Los campesinos están afectos a variadas condiciones que los pueden hacer vulnerables. Este colectivo es muy variado, puede estar compuesto tanto por sujetos vulnerables de una o más categorías, que en todo caso, lo componen todas las personas naturales o físicas que tienen una relación directa con la tierra y la naturaleza a través de la obtención de alimentos y de productos agrícolas al trabajar la tierra, incluyendo a los sin tierra. ${ }^{52}$ Como su principal labor y fuente de recursos, que es la agricultura, depende de factores climáticos, como sequias, inundaciones, entre otras catástrofes naturales, lo que hace inestable y por tanto vulnerable su actividad. Aún más, hoy no sólo encontramos a los campesinos tradicionales (abastecimiento propio o de pocos), sino que a los productores (abastecimiento de los demás). Éstos últimos dependen además de otros factores externos a ellos, distintos de los climáticos, para realizar su labor. ${ }^{53}$

Por otro lado, aunque los campesinos cumplan un rol fundamental en la sociedad, al mismo tiempo constituyen cerca del 80\% de las personas que padecen hambre. Ello, aunque sean la base de la alimentación mundial a nivel nacional e internacional, y, especialmente en los países en vías de desarrollo, donde son cruciales para la alimentación del país. Además, son víctimas de discriminación y violaciones sistemáticas de sus derechos humanos. Son algunas de las causas que, sumada a la inestabilidad de sus labores, propias de la

\footnotetext{
49 Los primeros problemas que hay que sortear por la herencia de las tradiciones procesales civiles, es que se entienden las vulneraciones como individuales, a lo más, un conjunto de ellas, similar a la relación jurídica acreedor con el deudor, con un paradigma de derecho decimonónico contractual y/o de derecho de daños. Es el interés individualmente protegido por tanto lo que tiene acción o recurso judicial. Sin embargo, esa estructuración del derecho a recurso efectivo no da cabida ante ciertos casos, de bienes jurídicos comunes, especialmente en los de titularidad colectiva, como lo puede ser la historia de una comunidad o la comunidad misma en COURTIS, Christian. El derecho a un recurso rápido, sencillo y efectivo frente a afectaciones colectivas de derechos humanos. Revista Iberoamericana de Derecho Procesal Constitucional, Argentina, n. 5, pp. 33-65. 2006.

50 LÓPEZ CALERA, Nicolás María. ¿Hay derechos colectivos? Individualidad y socialidad en la teoría de los derechos. Editorial Ariel, Barcelona. 2000.

51 COURTIS, Christian. El derecho a un recurso rápido, sencillo y efectivo frente a afectaciones colectivas de derechos humanos. Revista Iberoamericana de Derecho Procesal Constitucional, Argentina, n. 5, 2006, pp. 33-65.

52 FIAN INTERNACIONAL. Los campesinos y las campesinas necesitan mayor protección, 2012. Disponible en: http://www. fian.org/fileadmin/media/publications/2012.09.03_-_Advocacy_note_-_Peasants_need_more_protection_SP.pdf Acceso: 8 septiembre 2016.

53 VALLEJO NIETO, Mirna Isela, GURRI GARCÍA, Francisco Delfín, MOLINA ROSALES, Dolores Ofelia. Política y cultura, México, n. 36, 2011, pp. 71-98.
} 
agricultura, que se consideran como grupo de especial protección. ${ }^{54}$

En el caso de la Defensoría del Pueblo de Bolivia se reconoce a los campesinos como un grupo de especial protección, pero lo hace sumando a los pueblos indígenas, ${ }^{55}$ los que además en muchas ocasiones se fusionan en uno, es decir, pueden ser pueblos originarios y además campesinos. El Defensor en el área de la salud ha denunciado la mayor y preocupante tasa de mortalidad infantil en zonas rurales; en educación que el alfabetismo en mujeres indígenas rurales llega al 58,3 \%; ${ }^{56}$ y en participación política que aún no se han llevado diálogos de acuerdo a lo que sentenció el Tribunal Constitucional Plurinacional, "El Órgano Ejecutivo, en cumplimiento de sus funciones constitucionales, y en resguardo de los derechos de los pueblos indígena originario campesinos, debe propiciar y facilitar el diálogo necesario con dichos pueblos, a objeto de que a partir de la concertación, no sólo se desarrolle la consulta, sino que se concreten todos los planes y proyectos no sean únicamente de beneficio de dichos pueblos, sino también los que involucran el interés nacional", ${ }^{57}$ entre otras actuaciones.

Colombia en esta materia contempla a la Defensoría Delegada para Asuntos Agrarios y Tierras, dependiente de la Defensoría del Pueblo, la que está a disposición de los campesinos y población rural. En ese sentido, su objeto es promover, proteger y velar por la garantía de sus derechos humanos. Su actividad se enfoca en la disminución de la diferencia entre el goce efectivo de derechos, el que es altamente inferior de campesinos y habitantes respecto a las áreas urbanas. ${ }^{58}$ En tal sentido, el Defensor respecto de la vulnerabilidad de los campesinos, ha dicho respondiendo a la siguiente pregunta:

"¿Por qué las comunidades campesinas siempre han tenido mayores dificultades para la garantía de sus derechos si se compara con quienes viven en las ciudades?

Porque las políticas públicas han tenido un sesgo en lo urbano, de manera que las inversiones públicas siempre han tenido a las poblaciones campesinas y rurales en un renglón de poca importancia. Este constituye uno de los desafíos más grandes para el Estado colombiano en su conjunto, lograr que las acciones en favor de los derechos de los campesinos transformen el desequilibrio que existe en el goce efectivo de derechos de quienes viven en el campo, el cual resulta altamente inferior con relación a los habitantes de las áreas urbanas". 59

La Defensoría en Colombia no sólo supervisa, sino que también informa al sector. En tal sentido, destaca, entre otras, guías informativas, como la de derecho a acceso al crédito, ${ }^{60}$ de derecho a la participación de los campesinos, y sobre el derecho a la tierra y territorio de los campesinos, ${ }^{61}$ entre otras.

54 FIAN INTERNACIONAL. Los campesinos y las campesinas necesitan mayor protección, 2012. Disponible en: http://www. fian.org/fileadmin/media/publications/2012.09.03_-_Advocacy_note_-_Peasants_need_more_protection_SP.pdf Acceso: 8 septiembre 2016.

55 En el año 2012, el Centro Latinoamericano y Caribeño de Demografía ha manifestado que la población indígena de Bolivia llega a representar 62,2 \% de total del país. SOL DE PANDO. Bolivia es el país más indígena de América Latina, 9 de agosto de 2015. Disponible en: http://www.soldepando.com/httpwww-soldepando-comp26343/ Acceso: 16 octubre 2020.

56 BOLIVIA. Defensoría del Pueblo. XV Informe a la Asamblea Legislativa Plurinacional. 2012. Disponible en: https://www. defensoria.gob.bo/uploads/files/xv-informe-a-la-asamblea-legislativa-plurinacional.pdf Acceso: 16 octubre 2020.

57 BOLIVIA. Tribunal Constitucional Plurinacional. STC 0300/2012, de 18 de junio de 2012, Sentencia de sala plena, parte reso-

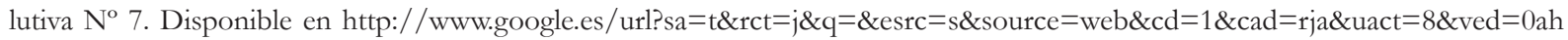
UKEwj_88y7renOAhWH0RoKHVi3AEsQFggcMAA\&url=http $\% 3 \mathrm{~A} \% 2 \mathrm{~F} \% 2 \mathrm{Fwww}$.fundacionconstruir.org $\% 2 \mathrm{Findex}$.php $\% 2 \mathrm{Fj}$ urisprudencia1\%2Fdescargar $\% 2$ Farchivo\%2FSENTENCIACONSTITUCIONALPLURINACIONAL0300_54.pdf\&usg=AFQj CNHetXNiXtJR3mBx2MjaA683cQZ7ZA Acceso: 16 octubre 2020.

58 COLOMBIA. Defensoría del Pueblo. Defensoría Delegada para Asuntos Agrarios y Tierras. Disponible en: http://www.defensoria.gov.co/es/public/defensoriasdelegadas/3472/Defensor\%C3\%ADa-Delegada-para-Asuntos-Agrarios-y-Tierras.htm Acceso: 30 agosto 2016].

59 COLOMBIA. Defensoría del Pueblo. Derechos de los campesinos colombianos, noviembre de 2015, Bogotá. Disponible en: http://www.defensoria.gov.co/public/pdf/Cartilla_derechos_de_los_campesinos.pdf Acceso: 16 octubre 2020.

60 COLOMBIA. Defensoría del Pueblo. Derecho a Acceder a Fuentes de Financiamiento. Disponible en: http://www.defensoria. gov.co/attachment/1166/Guia\%20de\%20Derecho\%20Acceso\%20al\%20Crédito.pdf Acceso: 16 octubre 2020.

61 COLOMBIA. Defensoría del Pueblo. Serie Guía de Derechos de los Campesinos Colombianos. Derecho a la participación de los hombres y mujeres campesinas. Disponible en: http://www.defensoria.gov.co/attachment/1167/Guias $\% 20$ de $\% 20$ derecho $\% 20$ a\%20la\%20participación\%20de\%20los\%20campesinos\%20en\%20Colombia.pdf Acceso: 16 octubre 2020. 
Sin embargo, otros países a pesar de tener una importante población rural no la consideran como grupo de especial protección a enfocarse, al menos expresamente. Por nombrar un caso, el de Perú, que en 2009 tenía 7.887.301 de población rural y urbana 20.594.600, ${ }^{62}$ y en 2015 rural de 7.257.989. ${ }^{63}$ Así, en su Defensoría del Pueblo no se divisa como conjunto especial a los campesinos o a la población rural. ${ }^{64}$ Tampoco el Defensor del Pueblo en España ${ }^{65}$ aunque el territorio rural abarque el 90\% donde reside el 20\% de la población al año 2009. ${ }^{66}$ Lo mismo sucede con Argentina, que separa a la población, en el año 2010 en rural agrupada (1.307.701) y rural dispersa (2.292.063) de un total del país de 40.117.096, ${ }^{67}$ en que el Defensor del Pueblo de la Nación no los considera especialmente de protección. ${ }^{68}$

\subsection{Víctimas de delitos}

En general se otorga una mayor protección a las víctimas de delitos que sean especialmente vulnerables, ya sea por la naturaleza de la víctima, niños, niñas, adolescentes, personas con discapacidad, o bien, sea por la gravedad del delito. En este aspecto, por ejemplo, la Directiva 2012/29 de la Unión Europea señala al efecto a los delitos de terrorismo, trata de seres humanos, explotación sexual, violencia de género, o discriminación. El objetivo de esto es evitar una victimización secundaria, como podría darse ante intimidación, represalias o reiteración del delito y por tanto de la violación de derechos. La idea es proteger los derechos de las víctimas especialmente vulnerables de forma inmediata para resguardar su vida, integridad, libertad, honor, intimidad, entre otros. No sólo a nivel preventivo, también la victima necesita que sea reparada o al menos aliviada respecto de sus derechos afectados. ${ }^{69}$

A pesar de todo lo anterior, las víctimas en los nuevos sistemas penales son en general consideradas como protagonistas olvidadas, y, quedan en ocasiones sujetas al desamparo institucional, situación que en un Estado de Derecho y por humanidad no puede tolerarse. Lo tradicional de las legislaciones de distintos países es que han contemplado al delincuente ignorando a la víctima, sin tener presente la victimización que ha provocado daños severos difíciles o imposibles de reparar, ya que involucra lo profundo de la integridad de una persona, tanto físico o mental, afectando sus relaciones sociales y familiares, situación económica, jurídica entre otras. De manera entonces que la despreocupación o abandono de las víctimas, la lesión a sus derechos humanos, la ausencia o ineficaz política criminal, la impunidad y la inexistencia o poco adecuadas políticas para reparar los daños de las víctimas son razones suficientes para que el Estado busque propuestas para la atención rápida y eficaz de las víctimas de delitos. ${ }^{70}$

${ }^{62}$ PERÚ. Instituto Nacional de Estadísticas e Informática. Perú: Estimaciones y Proyecciones de Población Urbana y Rural por Sexo y Edades Quinquenales, Según Departamento, 200-2015, Boletín Especial No 19, diciembre 2009, Lima. Disponible en http:/ / proyectos.inei.gob.pe/web/biblioineipub/bancopub/Est/Lib0844/libro.pdf Acceso: 16 octubre 2020.

63 PERÚ. Instituto Nacional de Estadísticas e Informática. Cuadros Estadísticos de Población Total, Urbana y Rural, por Sexo, según Departamento, 2000-2015. Disponible en: http://proyectos.inei.gob.pe/web/biblioineipub/bancopub/Est/Lib0844/ cap02_1.htm Acceso: 16 octubre 2020.

${ }^{64}$ PERÚ. Defensoría del Pueblo. Grupos de especial protección. Disponible en http://www.defensoria.gob.pe/ Acceso: 16 octubre 2020.

65 ESPAÑA. Defensor del Pueblo. Grupos sociales. Disponible en: https://www.defensordelpueblo.es/ Acceso: 16 octubre 2020.

66 ESPAÑA. Ministerio de Medio Ambiente y Medio Rural y Marino de España. Población y Sociedad Rural. Análisis y Prospectiva. Serie Agrinfo, n. 12, 2009. Disponible en: http://www.magrama.gob.es/es/ministerio/servicios/analisis-y-prospectiva/ Agrinfo12_tcm7-161562.pdf Acceso: 16 octubre 2020.

67 ARGENTINA. Ministerio de Defensa. Población de la República Argentina. Datos año 2010. Disponible en: http://www.ign. gob.ar/NuestrasActividades/Geografia/DatosArgentina/Poblacion Acceso: 16 octubre 2020.

68 ARGENTINA. Defensor del Pueblo. Grupos vulnerables. Disponible en: http://www.dpn.gob.ar/vulnerables.php Acceso: 16 octubre 2020

69 REQUEJO CONDE, Carmen. Víctimas especialmente vulnerables. Tratamiento penal. En: Good practices for protecting victims. Inside and outside the criminal process. 2016. Disponible en: http://www.protectingvictims.eu/upload/pages/67/Victimas. it.en.pdf Acceso: 16 octubre 2020.

70 MÉXICO. Comisión de Derechos Humanos del Estado de Hidalgo. Grupos vulnerables. Disponible en: http://www.cdhhgo. org/home/images/pdf/GRUPOS\%20VULNERABLES\%20WEB.pdf Acceso: 29 agosto 2016. 
Por todas esas razones, muchas Defensorías actualmente consideran a las víctimas de delitos como grupos vulnerables. En ese sentido, el Defensor del Pueblo español se refiere, como habíamos señalado, a las víctimas de violencia de género, pero también a las del terrorismo. En este último aspecto, señala que es un deber del Estado atender a las víctimas, considerando que España tiene una legislación solidaria y de protección avanzada en la materia, pero aquello no impide a que se generen problemáticas, ya sean normativas o de actuación en casos concretos. El Defensor centra su actividad en estos asuntos en indemnizaciones, prestaciones sociales, reconocimiento de condición de víctima, derechos de los amenazados y colabora con asociaciones afines. ${ }^{71}$

Además, le es relevante la preservación de la memoria histórica. Es así como la Defensora del Pueblo, doña Soledad Becerril Bustamante ha señalado en 2016 al respecto que, "¿Y Las víctimas del terrorismo? Yo creo que siempre, siempre, tendrán motivos para la queja. Han pagado con sus vidas el odio, la venganza, el fanatismo contra valores de toda una sociedad o con el fin de hacer imposible la democracia como fue el objetivo de la banda terrorista ET A". ${ }^{72}$

Hay otros países que no consideran expresamente como grupo especial de protección a las víctimas de delitos, como ocurre en Argentina con el Defensor del Pueblo de la Nación, ${ }^{73}$ ni Costa Rica, ${ }^{74}$ tampoco Colombia, ${ }^{75}$ lo mismo sucede en Perú. ${ }^{76} \mathrm{Y}$, para el caso de Chile es fundamental considerar a esta categoría, dado que, inclusive se ha constitucionalizado a la víctima. De hecho, se ha determinado que debe haber un órgano del Estado especializado para su protección. Sin embargo, aún no se ha creado, lo que puede generar una omisión del legislador inconstitucional, ${ }^{77}$ pero que puede de momento ser paliada con otras instituciones en su defensa.

\subsection{Personas con enfermedades crónicas}

Las enfermedades crónicas son un factor que aumenta la vulnerabilidad. Es así como en muchos países no sólo afecta el quehacer diario, sino que es una de las principales causas de deterioro de la salud, incapacidad, y, hasta de muerte. En 2005, se calcula que aproximadamente treinta y cinco millones murieron a causa de enfermedades no transmisibles, principalmente relativas a las cardiovasculares, diabetes, cáncer y respiratorias. Y, aunque la mayoría de estas muertes suceda en países de ingresos bajos, lo trascendental es la ausencia de políticas públicas para la prevención de la enfermedad. ${ }^{78}$

Dicha vulnerabilidad se agrava cuando además se conjugan otras vulnerabilidades. Por ejemplo, en el caso de las enfermedades crónicas en los niños, que tienen que superar su crecimiento ya sea fisiológico o en sus relaciones humanas, emocionales y cognitivas, que muchas veces es complejo debido a la propia enfermedad. En tal sentido, no sólo debe observarse la salud, sino que todo lo demás que les afecta. De manera que la enfermedad crónica infantil y todo lo que conlleva es un factor de riesgo para el desarrollo

\footnotetext{
71 ESPAÑA. Defensor del Pueblo. Víctimas del terrorismo. Disponible en: https://www.defensordelpueblo.es/grupo-social/ victimas-del-terrorismo/ Acceso: 16 octubre 2020.

72 ESPAÑA. Defensor del Pueblo. La Defensora del Pueblo habla sobre Víctimas del Terrorismo, Conferencia de 3 de mayo de 2016 en Forum Europa. Disponible en: https://www.defensordelpueblo.es/wp-content/uploads/2016/05/Forum-Europa06-Victimas-del-terrorismo-con-titulo.mp4 Acceso: 16 octubre 2020.

73 ARGENTINA. Defensor del Pueblo. Grupos vulnerables. Disponible en: http://www.dpn.gob.ar/vulnerables.php Acceso: 16 octubre 2020.

${ }^{74}$ COSTA RICA. Defensoría de los Habitantes. Disponible en: http://www.dhr.go.cr/ Acceso: 16 octubre 2020.

75 COLOMBIA. Defensoría del Pueblo. Defensorías delegadas. Disponible en: https://www.defensoria.gov.co/es/\#delegadas Acceso: 16 octubre 2020.

76 PERÚ. Defensoría del Pueblo. Grupos de especial protección. Disponible en http://www.defensoria.gob.pe/ Acceso: 16 octubre 2020.

77 PEREDO, Marcela. La constitucionalización del derecho a la defensa de las víctimas en Chile. Revista Brasileira de Políticas Públicas, Brasilia, Brasil, v. 10. n. 1, pp. 285-312. 2020.

78 VEGA ANGARITA, O.M. y GONZÁLEZ ESCOBAR, D.S. Apoyo social: elemento clave en el afrontamiento de la enfermedad crónica. Enfermería Global, España, n. 16, pp. 1-11. 2009.
} 
de los niños. ${ }^{79}$ Mismo razonamiento es replicable a los adolescentes que también están en crecimiento y desarrollo personal.

Así, hay algunos ejemplos concretos sobre enfermedades crónicas, inclusive sin resultado a próxima muerte. En efecto, el Defensor del Pueblo de España reconoce a las personas celiacas como un colectivo de especial protección. Su enfoque es que la Administración reconozca las circunstancias especiales de los celiacos, sobre todo respecto de la adquisición productos sin gluten para que sean más accesibles, de manera de no generar o mantener una desigualdad. ${ }^{80}$ En esta iniciativa más o menos reciente, destacan algunos resultados de una encuesta del Defensor realizada en junio y julio de 2016, recibiendo 12.059 respuestas on line, tales como que el $25 \%$ no se considera bien informado sobre el tratamiento para celiacos, que el 37\% valora como mala la atención de su enfermedad. ${ }^{81}$

Otro ejemplo lo constituye Perú, en que su Defensoría del Pueblo considera a las personas con VIH/ Sida como colectivo de especial protección. Es así porque reduce la expectativa de vida considerablemente, detiene el crecimiento económico y profundiza la pobreza a quien lo padece y a sus cercanos, lo que genera desigualdad. No sólo afecta en aquello. Además, a la Defensoría han llegado casos de discriminación de estas personas, en centros laborales, escuelas y servicios de salud. Se dedica también a supervisar a los servicios de prevención, atención y tratamiento en los establecimientos a cargo del Ministerio de Salud. ${ }^{82}$ Destaca además en su cometido informes sobre la temática, analizando casos cualitativamente ${ }^{83}$ como generales cuantitativos. $^{84}$

\subsection{Personas de especial protección por circunstancias particulares del país}

En general, los grupos anteriormente expuestos son comunes en la mayoría de las naciones. No obstante, también hay colectivos que son significativos en un determinado país o países. En adelante se dan los casos de la comunidad gitana en Europa y particularmente el Defensor del Pueblo de España y el caso del conflicto interno armado de Colombia. Además, sobre asuntos de deudores hipotecarios en España, que, a pesar de que en otros países también puede haber dicha problemática, es el Defensor del Pueblo español que los considera como grupo de especial protección.

En muchas ocasiones la comunidad gitana ha sido discriminada, ya sea históricamente o incluso de forma más o menos reciente como ocurrió con la expulsión de aquel colectivo en las principales capitales europeas en 2010. De ahí que se ha cuestionado si los gitanos son europeos de tercera. En dicha fecha comenzó Francia con la política de endurecimiento contra los que se denominaron "gente de viaje", luego Italia, Alemania, Dinamarca y Suecia. En el caso de París, había gitanos que se habían asentado a sus afueras en caravanas durante más de cuatros años, se dedicaban en general a la recolección de metal y no tenían en general acceso a empleos formales. ${ }^{85}$

En España el Defensor del Pueblo considera a la comunidad gitana como un grupo de especial protec-

\footnotetext{
CASTRO, Elisa Kern de y MORENO-JIMÉMNEZ, Bernardo. Resiliencia en niños enfermos crónicos: aspectos teóricos. Psicología em estudo, Brasil, v. 12, n. 1, 2007, pp. 81-86.

80 ESPAÑA. Defensor del Pueblo. Celiacos. Disponible en: https://www.defensordelpueblo.es/grupo-social/celiacos/ Acceso: 16 octubre 2020.

81 ESPAÑA. Defensor del Pueblo. Encuesta a personas celíacas: Primeros resultados, 28 de julio de 2016. Disponible en: https:// www.defensordelpueblo.es/noticias/encuesta-a-personas-celiacas-primeros-resultados-2/ Acceso: 16 octubre 2020.

82 PERÚ. Defensoría del Pueblo. Personas que viven con VIH. Disponible en: http://www.defensoria.gob.pe/grupos-eatencion. php?des=16 Acceso: 16 octubre 2020.

83 PERÚ. Defensoría del Pueblo. Fortaleciendo la respuesta frente a la epidemia del VIH/Sida: Supervisión de los servicios de prevención, atención y tratamiento del VIH/Sida. Informe defensorial No 89. 2005.

84 PERÚ. Defensoría del Pueblo. La infección de ocho pacientes con VIH por transfusión de sangre donada en el Instituto Especializado Materno Perinatal. Informe defensorial No 143. 2009.

85 MACÍAS LEÓN, Almudena. Gitanos europeos: ¿Ciudadanos de tercera? En: GARCÍA CASTAÑO, Francisco Javier y KRESSOVA, Nina (coordinadores). Actas del I Congreso Internacional sobre Migraciones en Andalucía. Granada, 2011, pp. 957-966.
} 
ción. ${ }^{86}$ Los gitanos en España han sido parte de la ciudadanía ibérica desde comienzos del siglo XV, siendo hoy en día aproximadamente en España 650.00 personas, concentrándose la mayor parte de ellos en Andalucía (270.000), Cataluña (80.000), Madrid (60.000), la Comunidad Valenciana (52.000). ${ }^{87}$

En efecto, los gitanos en muchas ocasiones son víctimas de discriminación. Pertenecer a dicho colectivo implica tal estigma que muchos optan por esconderlo, como lo hizo Ahmed Mustafá y sus parientes, huidos de la guerra de Siria, quienes afirmaron que no eran gitanos, sino que turcomanos ${ }^{88}$ Sin embargo, a pesar de que hay avances en su integración en España, existen situaciones que requieren preocupación de los poderes públicos y de toda la sociedad para conseguir que puedan ejercer sus derechos en un contexto de igualdad. En ese sentido el Defensor colabora con distintas asociaciones para una real integración de la comunidad gitana, además centra su actividad en la eliminación de estereotipos que afectan, de manera de garantizar la igualdad de oportunidades para los que pertenezcan a dicho colectivo. ${ }^{89}$

Por otro lado, en el caso colombiano existe la Defensoría Delegada para la Orientación y Asesoría de las Víctimas del Conflicto Armado interno, que es una sección de la Defensoría del Pueblo. ${ }^{90}$ Como es sabido, la guerra que ha tenido Colombia en su país durante cincuenta años al año 2016, ha traído aproximadamente 220.000 muertos, 45.000 desaparecidos y desplazados, lo que ha generado a un grupo de especial protección, que son las víctimas del conflicto, ya sea directa o indirectamente como a sus familiares. En efecto, no obstante, a los acuerdos de paz que se están llevando a cabo en el año 2016 entre el Gobierno y las Fuerzas Armadas Revolucionarias de Colombia (FARC), ${ }^{91}$ habrá víctimas y sus familiares que querrán ver resarcidos sus derechos, quizás siendo minoría frente a los necesarios acuerdos de paz.

En su actividad, la mencionada Defensoría Delegada destaca la denominada Estrategia de Orientación Psicojurídica, que otorga asesoría y acompañamiento, precisando posibilidades de participación en procesos judiciales o administrativos sobre reparación de sus intereses. Asimismo, la estructuración del programa de atención integral de víctimas del conflicto armado. También una serie de actuaciones derivadas de la ley 1448 de 2011, ${ }^{92}$ entre otras: la recepción de declaraciones como requisito de acceso al registro único de víctimas; asistencia legal que procura lograr el acceso al registro frente a las decisiones de no inclusión; orientación para el trámite de registro de tierras y modalidades de restitución; asesoría especializada frente a las medidas de asistencia y de reparación integral; presentación de solicitudes de revisión sobre decisiones de indemnización administrativa; coadyuvar en el seguimiento y evaluación del cumplimiento de la ley. ${ }^{93}$

También es un caso especial de España, pero que puede darse en todo el mundo, es el de los deudores hipotecarios, que han sido considerados como grupo de especial protección por el Defensor del Pueblo español. En tal sentido, se indica que la normativa del mercado hipotecario debe respetar el derecho a una

\footnotetext{
86 ESPAÑA. Defensor del Pueblo. Comunidad gitana. Disponible en: https://www.defensordelpueblo.es/grupo-social/gitanos/ Acceso: 16 octubre 2020.

87 FUNDACIÓN SECRETARIADO GENERAL GITANO. Observatorio 02. Empleo y Comunidad Gitana, Madrid, 2003.

88 IRIARTE, Daniel. El mapa de los gitanos: una población que conecta España con Rusia, 27 de octubre de 2013. Disponible en: http://www.elconfidencial.com/mundo/2013-10-27/el-mapa-de-los-gitanos-una-poblacion-que-conecta-espana-con-rusia_46284/ Acceso: 16 octubre 2020.

89 ESPAÑA. Defensor del Pueblo. Comunidad gitana. Disponible en: https://www.defensordelpueblo.es/grupo-social/gitanos/ Acceso: 16 octubre 2020.

90 COLOMBIA. Defensoría del Pueblo. Defensoría Delegada para la Orientación y Asesoría de las Víctimas del Conflicto Armado interno. Disponible en: http://www.defensoria.gov.co/es/public/defensoriasdelegadas/1448/Para-la-orientaci\%C3\%B3n-yasesor\%C3\%ADa-de-v\%CC3\%ADctimas-del-conflicto-armado-Interno.htm Acceso 25 agosto 2016.

91 LAFUENTE, Javier. Colombia abre nueva era al lograr un acuerdo de paz con las FARC tras 52 años de guerra, 25 de agosto de 2016. Disponible en: http://internacional.elpais.com/internacional/2016/08/24/colombia/1472064662_537059.html Acceso: 16 octubre 2020.

92 COLOMBIA. Ley 1448 de 2011, de 10 de junio, por la cual se dictan medidas de atención, asistencia y reparación integral a las víctimas del conflicto armado interno y se dictan otras disposiciones. Disponible en: http://www.alcaldiabogota.gov.co/sisjur/ normas/Norma1.jsp?i=43043 Acceso: 16 octubre 2020.

93 COLOMBIA. Defensoría del Pueblo. Defensoría Delegada para la Orientación y Asesoría de las Víctimas del Conflicto Armado interno. Disponible en: http://www.defensoria.gov.co/es/public/defensoriasdelegadas/1448/Para-la-orientaci\%CC3\%B3n-yasesor $\%$ C3\%ADa-de-v\%C3\%ADctimas-del-conflicto-armado-Interno.htm Acceso: 25 agosto 2016.
} 
vivienda digna y los demás derechos constitucionales ligados. Esto, a propósito de que con la crisis económica muchas personas no pueden pagar sus cuotas hipotecarias. ${ }^{94}$

La insolvencia hipotecaria ha sido de bastante relevancia para el Defensor, destacando informes, estudios y propuestas en favor de los deudores hipotecarios. ${ }^{95}$ En ese sentido, ha hecho una serie de recomendaciones basado en derecho comparado y en instituciones de importancia, como del Fondo Monetario Internacional. En tal sentido, y que evidencia el trabajo del Defensor, es ejemplar la siguiente recomendación que ha hecho al respecto:

"1. Regular ex novo un procedimiento singular de insolvencia de los particulares o consumidores, independiente del resto de los procedimientos existentes en el ordenamiento jurídico, basado en la cultura del pago y con la previsión de liberación de deudas remanentes, tras la liquidación del patrimonio, siguiendo la recomendación efectuada por el Fondo Monetario Internacional. Para el cumplimiento de este objetivo se recomienda abordar las reformas normativas necesarias en el orden civil, mercantil, administrativo y procesal". ${ }^{96}$

\section{Conclusiones}

Como se ha revisado, el INDH en sus 10 años de historia se ha enfocado en una serie de colectividades generando inclusive una base documental al respecto. Ello ha sido consecuencia dado que muchos de estos grupos son vulnerables, o bien, aunque en ciertos casos no sea necesariamente con un alto grado de vulnerabilidad, actúa guiado en la búsqueda de igualdad en el ejercicio de derechos de ciertos colectivos. Así, se ha preocupado de personas relacionadas con temas sobre diversidades sexuales, mujeres, niños, niñas y adolescentes, adultos mayores, personas con discapacidad, migrantes, privadas de libertad, refugiados y pueblos indígenas. Sea por una o por otra razón, de acuerdo con la literatura revisada se encuentra justificada la actuación del INDH en relación con estos grupos, lo que es relevante en la aplicación de la ley 20.405, en la promoción y protección de los derechos humanos, como también del artículo 5 de la Constitución como las garantías que contempla y de los tratados internacionales de derechos humanos ratificados por Chile y vigentes.

Sin embargo, también es menester revisar otros casos de vulnerabilidad o que ameriten una especial protección en la igualdad de ejercicio de los derechos, de acuerdo con las condiciones especiales de cada país. Como se advirtió, en el caso español con los deudores hipotecarios (por la crisis comenzada en 2008), o en Colombia por el conflicto armado interno con las FARC. Ello genera la necesidad de que el INDH replantee su visión, no solo de enfocarse en los colectivos que tienen dificultades en todas las naciones, sino que en aquellos casos particulares o que sean más profundos en el país. En ello la experiencia comparada puede servir de guía. Por ejemplo, como se ha evidenciado, en otros países las defensorías se enfocan en los campesinos. Gran parte del territorio de Chile es rural $\left(80 \%{ }^{97}\right.$ y, aunque los datos del último Censo ${ }^{98}$ de 2017 demuestran que la mayoría de las personas viven en zonas denominadas urbanas, el 12,2\% se establece en zonas rurales, lo que aumenta en determinadas regiones (Ñuble 30,6\%), La Araucanía (29,1\%) y Los Ríos $(28,3 \%)$. Ello equivale a preocuparse de cerca de 2.253.340 personas. ¿Acaso no sería un grupo especial en el cual centrarse? ¿En quién o quiénes más habría que enfocarse?

\footnotetext{
94 ESPAÑA. Defensor del Pueblo. Deudores hipotecarios. Disponible en https://www.defensordelpueblo.es/grupo-social/deudores-hipotecarios/ Acceso: 16 octubre 2020.

95 Así, por ejemplo, entre otros: ESPAÑA. Defensor del Pueblo. Viviendas protegidas vacías, Madrid, marzo, 2013; ESPAÑA. Defensor del Pueblo. La realidad catastral en España: perspectiva del Defensor del Pueblo, Madrid, marzo, 2012.

${ }_{96}$ ESPAÑA. Defensor del Pueblo. Crisis económica e insolvencia personal: actuaciones y propuestas del Defensor del Pueblo, Madrid, octubre, 2013.

97 ALONSO BERTAGGIA, Carla. 80\% de la superficie del país es rural. Disponible en: https://www.elmercurio.com/Campo/ Noticias/Noticias/2018/12/12/80-de-la-superficie-del-pais-es-rural.aspx?disp=1 Acceso: 19 octubre 2020.

98 ACEVEDO, Yolanda. Ruralidades en Chile: desafíos para el 2020. Disponible en: https://radio.uchile.cl/2019/08/22/ruralidades-en-chile-desafios-para-el-2020/\#: :text=El $\% 20$ Censo $\% 202017 \% 20$ muestra $\% 20 \mathrm{el}$, vive $\% 20 \mathrm{en} \% 201$ as $\% 20$ zonas $\% 20$ rurales Acceso: 19 octubre 2020.
} 


\section{Bibliografía.}

ALEMÁN, Jesús; TRUJILlO PÉREZ, María de los Ángeles; LÓPEZ SAUCEDO, María de la Luz. Los Adultos Mayores vistos por sí mismos: Percepciones de su persona y calidad de vida [Notas iníciales]. En: ACEVEDO ALEMÁN, Jesús, TRUJILLO PÉREZ, María de los Ángeles y LÓPEZ SAUCEDO, María de la Luz (coordinadores). La problemática de los grupos vulnerables: Visiones de la realidad, México, 2012. p. 289295.

ACEVEDO, Yolanda. Ruralidades en Chile: desafíos para el 2020. Disponible en: https://radio.uchile. cl/2019/08/22/ruralidades-en-chile-desafios-para-el-2020/\#: :text=El\%20Censo\%202017\%20muestra\%20el,vive\%20en\%20las\%20zonas\%20rurales. Acceso: 19 oct. 2020.

ALONSO BERTAGGIA, Carla. 80\% de la superficie del país es rural. Disponible en: https://www.elmercurio. com/Campo/Noticias/Noticias/2018/12/12/80-de-la-superficie-del-pais-es-rural.aspx?disp=1. Acceso: 19 oct. 2020.

ARGENTINA. Defensor del Pueblo. Grupos vulnerables. Disponible en: http://www.dpn.gob.ar/vulnerables.php. Acceso: 16 oct. 2020.

ARGENTINA. Ministerio de Defensa. Población de la República Argentina. Datos año 2010. Disponible en: http://www.ign.gob.ar/NuestrasActividades/Geografia/DatosArgentina/Poblacion. Acceso: 16 oct. 2020.

ARRIAGA BUENO, Reyna Alicia; CABALLERO RIVACOBA, María Teresa. La salud y el ingreso como indicadores de la calidad de vida del adulto mayor. Una reflexión desde el trabajo social. En: ACEVEDO ALEMÁN, Jesús; TRUJILLO PÉREZ, María de los Ángeles; LÓPEZ SAUCEDO, María de la Luz (coords.). La problemática de los grupos vulnerables: Visiones de la realidad, México, 2012. p. 231-245.

BOLIVIA. Defensoría del Pueblo. XV Informe a la Asamblea Legislativa Plurinacional. 2012. Disponible en: https://www.defensoria.gob.bo/uploads/files/xv-informe-a-la-asamblea-legislativa-plurinacional.pdf. Acceso: 16 oct. 2020 .

BOLIVIA. Tribunal Constitucional Plurinacional. STC 0300/2012, de 18 de junio de 2012, Sentencia de sala plena, parte resolutiva $\mathrm{N}^{\mathrm{o}}$ 7. Disponible en http:/ www.google.es/url? sa $=t \& r c t=j \& q=\& e s r c=s \&$ source $=\mathrm{w}$ eb\&cd $=1 \&$ cad $=$ rja\&uact $=8 \&$ ved $=0$ ahUKEwj_88y 7 renOAhWH0RoKHVi3AEsQFggcMAA\&url $=$ http $\%$ $3 \mathrm{~A} \% 2 \mathrm{~F} \% 2 \mathrm{Fwww}$.fundacionconstruir.org $\% 2 \mathrm{Findex}$.php $\% 2 \mathrm{Fjurisprudencia} 1 \% 2 \mathrm{Fdescargar} \% 2 \mathrm{Farchivo} \% 2$ FSENTENCIACONSTITUCIONALPLURINACIONAL0300_54.pdf\&usg=AFQjCNHetXNiXtJR3mB x2MjaA683cQZ7ZA. Acceso: 16 oct. 2020.

BUSTAMANTE, Jorge A. La vulnerabilidad de los migrantes internacionales como sujetos de Derechos Humanos. 2017. Disponible en: https://silo.tips/download/documento-sobre-mejores-practicas-relativas-a-trabajadores-migrantes. Acceso: 16 oct. 2020.

CABELLO GARZA, Martha Leticia; ÁVILA ORTÍZ, María Natividad; GARZA MONTOYA; Beatriz Gabriela. Obesidad: Los problemas de los grupos vulnerables. En: ACEVEDO ALEMÁN, Jesús; TRUJILLO PÉREZ, María de los Ángeles; LÓPEZ SAUCEDO, María de la Luz (coordinadores). La problemática de los grupos vulnerables: Visiones de la realidad, México, 2012. p. 73-88.

CARRASCO CARPIO, Concepción. La vulnerabilidad laboral de los extranjeros en España. Migraciones Internacionales, Tijuana, México, v. 8, n. 2, p. 41-72. 2015.

CASTRO, Elisa Kern de; MORENO-JIMÉMNEZ, Bernardo. Resiliencia en niños enfermos crónicos: aspectos teóricos. Psicología em estudo, Brasil, v. 12, n. 1, p. 81-86. 2007. 
CHILE. Corte Suprema. Roles 27697-2016, 68679-2016, 87743-2016, 87748-2016, 87876-2016, 92816-2016. Disponible en el expediente electrónico ingresando el rol indicado en: https://suprema.pjud.cl/SITSUPPORWEB/InicioAplicacion.do. Acceso: 16 feb. 2021.

CHILE. Decreto 100, de 22 de septiembre de 2005, que Fija el texto refundido, coordinado y sistematizado de la Constitución Politica de la República de Chile (última versión 23 de diciembre de 2020). Disponible en: https://www.bcn.cl/ leychile/navegar?idNorma=242302. Acceso: 17 feb. 2020.

CHILE. Instituto Nacional de Derechos Humanos. Informe Anual. Situación de los derechos humanos en Chile 2020. Disponible en: https://ia2020.indh.cl/informe/INFORME-INDH-2020.pdf. Acceso: 16 feb. 2021, pp. 140-151.

CHILE. Instituto Nacional de Derechos Humanos. Género y Grupos de Protección. Disponible en: https:// bibliotecadigital.indh.cl/handle/123456789/4. Acceso: 16 oct. 2020.

CHILE. Ley 20.405, de 10 de diciembre de 2009. Del Instituto Nacional de Derechos Humanos, última modificación de 25 de abril de 2019, Ley 21.154. Disponible en: https://www.bcn.cl/leychile/ navegar?idNorma=1008867. Acceso: 16 oct. 2020.

COLOMBIA. Defensoría del Pueblo. Defensoría Delegada para Asuntos Agrarios y Tierras. Disponible en: http://www.defensoria.gov.co/es/public/defensoriasdelegadas/3472/Defensor\%C3\%ADa-Delegada-para-Asuntos-Agrarios-y-Tierras.htm. Acceso: 30 ago. 2016.

COLOMBIA. Defensoría del Pueblo. Defensoría Delegada para la Orientación y Asesoría de las Victimas del Conficto Armado interno. Disponible en: http://www.defensoria.gov.co/es/public/defensoriasdelegadas/1448/ Para-la-orientaci $\% \mathrm{C} 3 \% \mathrm{~B} 3 \mathrm{n}$-y-asesor $\% \mathrm{C} 3 \% \mathrm{ADa}$-de-v $\% \mathrm{C} 3 \% \mathrm{ADctimas}$-del-conflicto-armado-Interno.htm. Acceso: 25 ago. 2016.

COLOMBIA. Defensoría del Pueblo. Defensorías delegadas. Disponible en: https://www.defensoria.gov.co/ es/\#delegadas. Acceso: 16 oct. 2020.

COLOMBIA. Defensoría del Pueblo. Derecho a Acceder a Fuentes de Financiamiento. Disponible en: http:// www.defensoria.gov.co/attachment/1166/Guia\%20de\%20Derecho\%20Acceso\%20al\%20Crédito.pdf. Acceso: 16 octubre 2020 .

COLOMBIA. Defensoría del Pueblo. Derechos de los campesinos colombianos, noviembre de 2015. Bogotá. Disponible en: http://www.defensoria.gov.co/public/pdf/Cartilla_derechos_de_los_campesinos.pdf. Acceso: 16 oct. 2020.

COLOMBIA. Defensoría del Pueblo. Serie Guía de Derechos de los Campesinos Colombianos. Derecho a la participación de los hombres y mujeres campesinas. Disponible en: http://www.defensoria.gov.co/attachment/1167/ Guias $\% 20$ de $\% 20$ derecho $\% 20 a \% 201 \mathrm{a} \% 20$ participación $\% 20 \mathrm{de} \% 201$ os $\% 20$ campesinos $\% 20 \mathrm{en} \% 20$ Colombia.pdf. Acceso: 16 oct. 2020.

COLOMBIA. Ley 1448 de 2011, de 10 de junio, por la cual se dictan medidas de atención, asistencia y reparación integral a las víctimas del conflicto armado interno y se dictan otras disposiciones. Disponible en: http:/ /www.alcaldiabogota. gov.co/sisjur/normas/Norma1.jsp?i=43043. Acceso: 16 oct. 2020.

COMITÉ INTERNACIONAL DE LA CRUZ ROJA. Privados de libertad. Ginebra. 2003. Disponible en: https://www.icrc.org/spa/assets/files/other/icrc_003_0685.pdf. Acceso: 16 oct. 2020.

COMISIÓN EUROPEA PARA LA DEMOCRACIA. Principios sobre la protección y la promoción de la institución del Defensor del Pueblo (Los Principios de Venecia). Disponible en: https://www.defensordelpueblo.es/wp-content/uploads/2019/04/Principios-de-Venecia-esp-versi\%C3\%B3n-29-03-19-1.pdf. Acceso: 01 mar. 2021. 
COSTA RICA. Defensoría de los Habitantes. Disponible en: http://www.dhr.go.cr/ Acceso: 16 octubre 2020. COURTIS, Christian. El derecho a un recurso rápido, sencillo y efectivo frente a afectaciones colectivas de derechos humanos. Revista Iberoamericana de Derecho Procesal Constitucional, Argentina, n. 5, p. 33-65. 2006.

CROSSO, Camila. El Derecho a la Educación de Personas con Discapacidad: impulsando el concepto de Educación Inclusiva. Revista Latinoamericana de Educación Inclusiva, Santiago, Chile, v. 4, n. 2, p. 79-95. 2010.

DÍAZ FUENZALIDA, Juan Pablo. ¿Son parte del bloque de constitucionalidad los principales tratados internacionales de derechos humanos de la ONU en Chile? Del texto positivo a la aplicación en tribunales de justicia. Revista Brasileira de Políticas Públicas, Brasilia, Brasil, v. 9. n. 1, p. 152-171. 2019.

DÍAZ FUENZALIDA, Juan Pablo. Un aporte a la protección de los derechos humanos en Latinoamérica: la actividad del Ombudsman Criollo en tribunales de justicia. Revista Brasileira de Políticas Públicas, Brasilia, v. 9. n. 2, p. 493-511. 2019.

DÍAZ TOLOSA, Regina Ingrid. Expulsion of aliens: the application of International Law by Chilean superior courts. Revista de Direito Internacional, Brasilia, Brasil, v. 17, n. 2, pp. 308-330. 2020.

ESPAÑA. Defensor del Pueblo. Celiacos. Disponible en: https://www.defensordelpueblo.es/grupo-social/ celiacos/. Acceso: 16 oct. 2020.

ESPAÑA. Defensor del Pueblo. Comunidad gitana. Disponible en: https://www.defensordelpueblo.es/grupo-social/gitanos/. Acceso: 16 oct. 2020.

ESPAÑA. Defensor del Pueblo. Crisis económica e insolvencia personal: actuaciones y propuestas del Defensor del Pueblo, Madrid, octubre, 2013.

ESPAÑA. Defensor del Pueblo. Deudores hipotecarios. Disponible en https://www.defensordelpueblo.es/ grupo-social/deudores-hipotecarios/. Acceso: 16 oct. 2020.

ESPAÑA. Defensor del Pueblo. Encuesta a personas celíacas: Primeros resultados, 28 de julio de 2016. Disponible en: https://www.defensordelpueblo.es/noticias/encuesta-a-personas-celiacas-primeros-resultados-2/. Acceso: 16 oct. 2020.

ESPAÑA. Defensor del Pueblo. Grupos sociales. Disponible en: https://www.defensordelpueblo.es/. Acceso: 16 oct. 2020.

ESPAÑA. Defensor del Pueblo. La Defensora del Pueblo habla sobre Victimas del Terrorismo, Conferencia de 3 de mayo de 2016 en Forum Europa. Disponible en: https:/ /www.defensordelpueblo.es/wp-content/uploads/2016/05/ Forum-Europa-06-Victimas-del-terrorismo-con-titulo.mp4. Acceso: 16 oct. 2020.

ESPAÑA. Defensor del Pueblo. La realidad catastral en España: perspectiva del Defensor del Pueblo, Madrid, marzo, 2012.

ESPAÑA. Defensor del Pueblo. Victimas del terrorismo. Disponible en: https://www.defensordelpueblo.es/ grupo-social/victimas-del-terrorismo/. Acceso: 16 oct. 2020.

ESPAÑA. Defensor del Pueblo. Viviendas protegidas vacías, Madrid, marzo, 2013.

ESPAÑA. Ministerio de Medio Ambiente y Medio Rural y Marino de España. Población y Sociedad Rural. Análisis y Prospectiva. Serie Agrinfo, n. 12, 2009. Disponible en: http://www.magrama.gob.es/es/ministerio/ servicios/analisis-y-prospectiva/Agrinfo12_tcm7-161562.pdf. Acceso: 16 oct. 2020.

ESPINOSA MUNGUÍA, María Socorro; CALZONCIT, José Luis; VALDEZ HUERTA, María del Rosario. Los Trabajadores Sociales ¿Un grupo vulnerable? En: ACEVEDO ALEMÁN, Jesús; TRUJILLO PÉREZ, María de los Ángeles; LÓPEZ SAUCEDO, María de la Luz (coord.). La problemática de los grupos vulnerables: Visiones de la realidad, México: Universidad Autónoma de Coahuila, 2012. p. 10-33. 
ESQUEMBRE CERDÁ, María del Mar. Feminismo y constitucionalismo crítico. En: GARCÍA HERRERA, Miguel Ángel, ASENSI SABATER, José y BALAGUER CALLEJÓN, Francisco (directores) Constitucionalismo Crítico: Liber amicorum Carlos de Cabo Martín, Tirant lo Blanch, España, v. 1, p. 391-402. 2016.

FIAN INTERNACIONAL. Los campesinos y las campesinas necesitan mayor protección. 2012. Disponible en: http://www.fian.org/fileadmin/media/publications/2012.09.03_-_Advocacy_note_-_Peasants_need_ more_protection_SP.pdf. Acceso: 8 sep. 2016.

FUNDACIÓN SECRETARIADO GENERAL GITANO. Observatorio 02. Empleo y Comunidad Gitana, Madrid, 2003.

GARCEZ CALIL, Mário Lúcio y MARKMAN, Debora. Direito, raça e gênero: elementos para a construção de uma teoría feminista do direito adequada ao feminismo negro. Revista Brasileira de Políticas Públicas, Brasilia, v. 10. n. 2, p. 173-195, 2020.

GÓNZALEZ PÉREZ, Luis Raúl. El sistema no-jurisdiccional de protección de los derechos humanos en México. Revista Ius, Puebla, México, v. 5, n. 28, p. 99-122, 2011.

HERNÁNDEZ SAMPIERI, Roberto; FERNÁNDEZ COLLADO, Carlos; BAPTISTA LUCIO, Pilar. Metodología de la Investigación, 6. ed. México: Mcgraw-Hill, 2013.

IRIARTE, Daniel. El mapa de los gitanos: una población que conecta España con Rusia, 27 de octubre de 2013. Disponible en: http://www.elconfidencial.com/mundo/2013-10-27/el-mapa-de-los-gitanos-una-poblacion-que-conecta-espana-con-rusia_46284/ Acceso: 16 oct. 2020.

JASSO OYERVIDES, Martha Virginia y LÓPEZ SAUCEDO, María de la Luz. La calidad de vida de los niños en la calle. En: ACEVEDO ALEMÁN, Jesús, TRUJILLO PÉREZ, María de los Ángeles y LÓPEZ SAUCEDO, María de la Luz (coordinadores). La problemática de los grupos vulnerables: Visiones de la realidad, México, pp. 172-190. 2012.

LAFUENTE, Javier. Colombia abre nueva era al lograr un acuerdo de paz con las FARC tras 52 años de guerra, 25 de agosto de 2016. Disponible en: http://internacional.elpais.com/internacional/2016/08/24/ colombia/1472064662_537059.html Acceso: 16 octubre 2020.

LÓPEZ CALERA, Nicolás María. ¿Hay derechos colectivos? Individualidad y socialidad en la teoría de los derechos. Editorial Ariel, Barcelona. 2000.

LOSANO MALDONADO, María Cecilia y GARCÍA HORTA, José Baltazar. El joven marginal y la educación formal. Reflexiones en torno a la inclusión y la equidad educativa. En: ACEVEDO ALEMÁN, Jesús, TRUJILLO PÉREZ, María de los Ángeles y LÓPEZ SAUCEDO, María de la Luz (coordinadores). La problemática de los grupos vulnerables: Visiones de la realidad, México, pp. 89-104. 2012.

MACÍAS LEÓN, Almudena. Gitanos europeos: ¿Ciudadanos de tercera? En: GARCÍA CASTAÑO, Francisco Javier y KRESSOVA, Nina (coordinadores). Actas del I Congreso Internacional sobre Migraciones en Andalucía, Granada, pp. 957-966. 2011.

MESTRIES, Francis. Los desplazados internos forzados: refugiados invisibles en su propia patria. El Cotidiano, Distrito Federal, México, n. 183, pp. 17-25. 2014.

MÉXICO. Comisión de Derechos Humanos del Estado de Hidalgo. Grupos vulnerables. Disponible en: http://www.cdhhgo.org/home/images/pdf/GRUPOS\%20VULNERABLES\%20WEB.pdf Acceso: 29 agosto 2016.

MÉXICO. Comisión Nacional de los Derechos Humanos. Diagnóstico de las Condiciones de Vulnerabilidad que Propician la Trata de Personas en México, 2009. Disponible en: http://www.iberopuebla.mx/ micrositios/observatorioviolencia/bibliotecavirtual/genero_\%20y_violencia/2diagnostico_trata_de_personas_ceidas_cndh.pdf Acceso: 29 agosto 2016. 
NACIONES UNIDAS. A/RES/48/134 el 20 de diciembre de 1993, Instituciones nacionales de promoción y protección de los derechos humanos. Disponible en: https://www.oas.org/dil/esp/Res_48-134_UN.pdf Acceso: 01 marzo 2021.

NACIONES UNIDAS. Principios rectores de los desplazamientos internos, 1998. Disponible en: http:// www.acnur.es/PDF/0022_20120416132756.pdf Acceso: 26 agosto 2016.

NACIONES UNIDAS. Protección de los más vulnerables, 2013. Disponible en: http://www.un.org/es/ humanitarian/overview/protection.shtml Acceso: 18 agosto 2016.

ONOFRE RODRÍGEZ, Dora Julia y CABELLO GARZA, Martha Leticia. Vulnerabilidad social en Adolescentes con Síndrome Metabólico. "Un problema mundial de índole social”. En: ACEVEDO ALEMÁN, Jesús; TRUJILLO PÉREZ, María de los Ángeles; LÓPEZ SAUCEDO, María de la Luz (coord.). La problemática de los grupos vulnerables: Visiones de la realidad, México, 2012. p. 164-171.

OYERVIDES VALDÉS, Lourdes. Un México Maduro y Enfermo Bucalmente. En: ACEVEDO ALEMÁN, Jesús; TRUJILLO PÉREZ, María de los Ángeles; LÓPEZ SAUCEDO, María de la Luz (coords.). La problemática de los grupos vulnerables: Visiones de la realidad, México, p. 265-288, 2012.

PEREDO, Marcela. La constitucionalización del derecho a la defensa de las víctimas en Chile. Revista Brasileira de Politicas Públicas, Brasilia, v. 10. n. 1, p. 285-312, 2020.

PERÚ. Defensoría del Pueblo. Fortaleciendo la respuesta frente a la epidemia del VIH/Sida: Supervisión de los servicios de prevención, atención y tratamiento del VIH/Sida. Informe defensorial No 89. 2005.

PERÚ. Defensoría del Pueblo. Grupos de especial protección. Disponible en http://www.defensoria.gob.pe/. Acceso: 16 oct. 2020.

PERÚ. Defensoría del Pueblo. La infección de ocho pacientes con VIH por transfusión de sangre donada en el Instituto Especializado Materno Perinatal. Informe defensorial No 143. 2009.

PERÚ. Defensoría del Pueblo. Personas que viven con VIH. Disponible en: http://www.defensoria.gob.pe/ grupos-eatencion.php?des=16. Acceso: 16 oct. 2020.

PERÚ. Instituto Nacional de Estadísticas e Informática. Cuadros Estadísticos de Población Total, Urbana y Rural, por Sexo, segín Departamento, 2000-2015. Disponible en: http://proyectos.inei.gob.pe/web/biblioineipub/ bancopub/Est/Lib0844/cap02_1.htm. Acceso: 16 oct. 2020.

PERÚ. Instituto Nacional de Estadísticas e Informática. Perú: Estimaciones y Proyecciones de Población Urbana y Rural por Sexo y Edades Quinquenales, Según Departamento, 200-2015, Boletín Especial No 19, diciembre 2009, Lima. Disponible en: http://proyectos.inei.gob.pe/web/biblioineipub/bancopub/Est/ Lib0844/libro.pdf. Acceso: 16 oct. 2020.

REAL ACADEMIA ESPAÑOLA. Discapacitado. Disponible en: http://dle.rae.es/?id=DrrzNuK. Acceso: 16 oct. 2020.

REQUEJO CONDE, Carmen. Víctimas especialmente vulnerables. Tratamiento penal. En: Good practices for protecting victims. Inside and outside the criminal process. 2016. Disponible en: http://www.protectingvictims.eu/upload/pages/67/Victimas.it.en.pdf. Acceso: 16 oct. 2020.

REYES, David de Jesús; AMADOR CORREDOR, Sandra R.; CHÁVEZ VALERIO, Cecilia G. Adolescencia y embarazo: supuestos e implicaciones en su estudio como grupo vulnerable. En: ACEVEDO ALEMÁN, Jesús; TRUJILLO PÉREZ, María de los Ángeles; LÓPEZ SAUCEDO, María de la Luz (coords). La problemática de los grupos vulnerables: Visiones de la realidad, México, 2012. p. 219-230.

ROCCATTI, Mireille. Los derechos de los indígenas en la legislación mexicana e investigación de violaciones a Derechos Humanos en comunidades indígenas. En: UNIVERSIDAD ALCALÁ DE HENARES. El Fortalecimiento del Ombudsman Iberoamericano. 1999. 
ROSAS VARGAS, Roció; JASSO MARTÍNEZ, Ivy Jacaranda; HUACUZ ELÍAS, Guadalupe. Mujeres indígenas y violencia de género en Michoacán. En: ACEVEDO ALEMÁN, Jesús; TRUJILLO PÉREZ, María de los Ángeles; LÓPEZ SAUCEDO, María de la Luz (coords.). La problemática de los grupos vulnerables: Visiones de la realidad, México, p. 150-163, 2012.

SALGADO DE SNYNER, V. Nelly; GONZÁLEZ VÁSQUEZ, Tonatiuh; BOJORQUEZ CHAPELA, Letza; INFANTE XIBILE, César. Vulnerabilidad social, salud y migración México-Estados Unidos. Salud Pública de México, Cuernavaca, México, v. 49, p. 8-10, 2007.

SÁNCHEZ ZORRILLA, Manuel. La metodología en la investigación jurídica: características peculiares y pautas generales para investigar en el derecho. Revista Telemática de Filosofía del Derecho, n. 14, p. 317-358, 2011.

SOL DE PANDO. Bolivia es el país más indígena de América Latina. 9 ago. 2015. Disponible en: http://www. soldepando.com/httpwww-soldepando-comp26343/. Acceso: 16 oct. 2020.

JAMBERSI, Karoline Strapasson; OLIVEIRA, Antonio Gonçalves. Orçamento para os direitos das crianças e adolescentes em Curitiba: plano e execução. Revista Brasileira de Políticas Públicas, Brasilia, v. 10. n. 1, p. 223-234, 2020.

TORO-ALFONSO, José. El Estado Actual de la Investigación Sobre la Discriminación Sexual. Terapia psicológica, Santiago, Chile, v. 30, n. 2, p. 71-76, 2012.

VALLEJO NIETO, Mirna Isela, GURRI GARCÍA, Francisco Delfín, MOLINA ROSALES, Dolores Ofelia. Política y cultura, México, n. 36, p. 71-98, 2011.

VEGA ANGARITA, O. M.; GONZÁLEZ ESCOBAR, D. S. Apoyo social: elemento clave en el afrontamiento de la enfermedad crónica. Enfermería Global, España, n. 16, p. 1-11, 2009.

VILLABELLA ARMENGOL, Carlos Manuel. Los métodos en la investigación jurídica. Algunas precisiones. En: GODÍNEZ MÉNDEZ, Wendy; GARCÍA PEÑA, José (coords.). Metodologías: enseñanza e investigación jurídicas, 40 años de vida académica. Homenaje a Jorge Witker, México, 2015. p. 921-953.

VITE PÉREZ, Miguel Ángel. La discapacidad en México desde la vulnerabilidad social. Polis, México, v. 8, n. 2, p. 153-173, 2012. 
Para publicar na revista Brasileira de Políticas Públicas, acesse o endereço eletrônico www.rbpp.uniceub.br

Observe as normas de publicação, para facilitar e agilizar o trabalho de edição. 